\title{
TRANSFORMACIONES DEL TRABAJO Y JUVENTUD: TEMAS DE BÚSQUEDA
}

\author{
FELIPE GHIARDO SOTO*
}

\begin{abstract}
RESUMEN
El artículo intenta conectar los cambios en las nuevas formas de ser joven con las transformaciones históricas del trabajo ocurridas en la segunda mitad del siglo XX. Se presenta parte de la discusión teórica que guía la reflexión de estos procesos como una manera de contextualizar el análisis de la conversación que producen jóvenes sobre el trabajo. Finalmente se intenta ligar los temas que ordenan los discursos de los jóvenes con algunas de las apuestas que circulan en el debate actual sobre el futuro del trabajo.
\end{abstract}

PALABRAS ClAVE: TRABAJO, JÓVENES, TRAYECTORIAS, DISCURSOS

* Centro de Estudios Sociales CIDPA. E-Mail: felipe@cidpa.cl. 


\title{
TRANSFORMAÇÕES DO TRABALHO E JUVENTUDE: TEMAS DE BUSCA
}

\begin{abstract}
RESUMO
$\mathrm{O}$ artigo procura relacionar as mudanças nas novas formas de ser jovem com as transformações históricas do trabalho ocorridas na segunda metade do século XX. Apresenta-se parte da discussão teórica que direciona a reflexão desses processos como uma maneira de contextualizar a análise do discurso dos jovens sobre o trabalho. Por fim, busca-se relacionar os temas que ordenam os discursos dos jovens com algumas das apostas que circulam no debate atual sobre o futuro do trabalho.
\end{abstract}

PALAVRAS-CHAVE: TRABALHO, JOVENS, TRAJETÓRIAS, DISCURSOS

\section{TRANSFORMATION IN WORK AND YOUTH: SEARCH TOPICS}

\begin{abstract}
This article attempts to connect changes of the new ways of youth with the historical transformations of work which occurred in the second half of the twentieth century. It highlights some of the theoretical discussions which guides the reflection of these processes as a way to contextualize the analysis of conversation produced by youth on the job. Finally, attempts to link the themes to give order to the speeches of youth which circulate with regards to different opinions on the current debate for the future of employment.
\end{abstract}

KEY WORDS: WORK, YOUTH, TRAJECTORY, SPEECH 


\section{TRANSFORMACIONES DEL TRABAJO Y SOCIEDAD}

UN TÓPICO QUE RECORRE la reflexión sobre la sociedad y la cultura contemporáneas es el de la transformación. Todo pareciera haber cambiado. Las figuras de lo sólido que pasó a líquido o se desvaneció en el aire, el uso de los prefijos neo y post, o del verbo advenir, expresan el sentimiento de unas generaciones que tuvieron la experiencia de vivir tiempos de profundas transformaciones en el orden mundial.

El trabajo es clave: lo que se transformó fue una forma de sociedad estructurada en base al trabajo. Trabajo en una fase específica del modo de producción capitalista: la fase de expansión y consolidación mundial del capitalismo industrial. Es la sociedad de la postguerra, de los diferentes tipos de socialismo, socialdemocracia y nacional-populismos, que fueron formas políticas de organizar el desarrollo industrial. Unos dirigiendo la economía desde el centro del aparato estatal; otros - las socialdemocracias y los Estados desarrollistas - fomentando la industrialización con recursos fiscales, regulando jurídicamente la relación empresarios/trabajadores, y asumiendo el «pleno empleo» como mecanismo de integración social (Sunkel, 2007). ${ }^{1} \mathrm{Al}$ trabajar se adquirían derechos sociales y políticos, se accedía a bienes de consumo, se adoptaban formas de vida, se participaba de espacios que eran fuente de identidades individuales y colectivas. Por eso algunos analistas las definen con razón como sociedades fundadas en el «paradigma» del trabajo.

Fue esta organización característica de los Estados benefactores europeos, del new deal norteamericano y los desarrollismos latinoamericanos la que cayó en crisis a comienzos de los setenta. La crisis fue también de la organización fordista del trabajo, que fue la forma en que se organizó la producción en esta fase del capitalismo industrial. Basado en

1 Denis Collin ofrece una buena explicación sobre el proceso: «La regulación keynesiana de la demanda permitía un crecimiento sostenido, ganancias honorables, y la progresión del empleo y del poder de compra. Detrás de tal situación idílica, existía la lucha de clases dura, el temor a la revolución al finalizar la segunda guerra mundial, el traumatismo político, social y moral que esta guerra había provocado y que incitaba incluso a las clases dirigentes a no querer volver a encontrarse en una situación semejante a la de los años $30 \mathrm{y}$, finalmente, el temor de la Unión Soviética a despecho de las seguridades que Stalin no había dejado de dar con respecto a su escrupuloso respeto por las fronteras de Yalta. Lo que cambió desde esa época, es el abandono de esa cooperación conflictiva y más o menos forzada» (Collin, 1998). 
el control de los tiempos de producción, el fordismo producía mercancías en masa a bajo costo que eran consumidos por la misma masa trabajadora del «pleno empleo». ${ }^{2}$ Así se aseguraba un ciclo de circulación soportado y a veces regulado por políticas de precios, protección social y provisión estatal de servicios públicos (cf. Gorz, 1998). Ese modelo de producción y acumulación fue el que entró en crisis. Las explicaciones han sido varias: las más triviales de la época se la atribuyeron a la inflación, la irresponsabilidad de los sindicatos, la inoperancia monetaria de los Estados y el alza del petróleo, pero en el fondo se trató de una crisis de acumulación del modelo: las empresas no estaban ganando todo lo que querían (Gamble y Walton, 1977). Para salir de la crisis el empresariado abandonó los postulados keynesianos, cambió la organización interna de las empresas y sus representantes ideológicos presionaron políticamente para reducir las funciones reguladoras de los Estados y la magnitud de los impuestos que servían para financiarlas. Esos fueron los primeros pasos para una reformulación completa del orden internacional. Los paradigmas de la industrialización y el desarrollo dominantes en gran parte de los países occidentales fueron reemplazados por el «fundamentalismo mercadocéntrico» (Sunkel, 2007). La producción se liberó a las fuerzas del mercado, ${ }^{3}$ el crecimiento se entregó a la empresa privada, los servicios públicos se privatizaron y el rol económico del Estado se redujo a subsidiar algunas actividades y arrojar salvavidas a los sacrificados por el sistema.

La avalancha de cambios fue veloz. La innovación tecnológica permitió a las empresas reducir la mano de obra, separó las operacio-

2 En rigor, el «pleno empleo» nunca llegó a ser tal: las tasas de desempleo en todos esos años bordearon el 5\% (Gamble y Walton, 1977).

3 Así lo explica André Gorz: «El fin del crecimiento 'fordista' dejó a las empresas dos caminos para intentar escapar del estancamiento: i) la conquista de porciones de mercado suplementarias y ii) la renovación acelerada de la gama de sus producciones, la obsolescencia acelerada de sus productos. Para la conquista de porciones suplementarias de mercado, los esfuerzos prometían ser más eficaces en la medida en que los mercados eran todavía relativamente 'vírgenes', en consecuencia, las firmas debían buscar hacer pie en los países 'emergentes'. En cuanto a la obsolescencia acelerada de los productos, no sólo exigía esfuerzos intensos y sostenidos en materia de innovación; exigía también la capacidad de producir en series cada vez más cortas a costos unitarios cada vez más bajos. Uno y otro camino imponían la ruptura con el modo de producción fordista» (Gorz, 1998). 
nes en una cadena de departamentos, muchas empezaron a trasladar sus centros productivos a países con mano de obra más barata, los excedentes de la producción los invirtieron en capital financiero, la aplicación intensiva de tecnología produjo desempleo estructural, parte del desempleo se absorbió en el sector de servicios privados, eso «tercerizó» fuertemente la estructura de la economía y el empleo, también volvió a feminizar la fuerza de trabajo, la crisis de principios de los ochenta propagó las reingenierías, el outsourcing, la flexibilidad, la separación por equipos de trabajo, eso agravó la anemia del sindicalismo, carta blanca para reducir, individualizar, desregular, desproteger y precarizar las relaciones laborales, y ayudar a que el desempleo estructural desembocara en informalidad masiva.

El análisis de estos procesos generó nuevos enfoques teóricos. Los trabajos de Touraine y de Bell sobre la sociedad postindustrial (Touraine, 1971; Bell, 1976) o del mismo Touraine sobre los «nuevos movimientos sociales» (Touraine, 1976) fueron algunas de las teorías sociológicas que se formularon la noción de cambio de época. El diagnóstico fue que ya no se trataba de una sociedad estructurada en clases, con identidades determinadas por posiciones en la estructura social, con actores definidos por su posición en las relaciones sociales de producción y representados por partidos que se disputaban el control del Estado y la economía. La organización de la producción ahora dependía cada vez más de la tecnología y el conocimiento, las pautas de acción de los individuos pasaban a ser cada vez más dirigidas por los manipuladores de símbolos, mientras la «clase obrera» dejaba de ser el único «sujeto histórico» para ser reemplazada por nuevos movimientos fundados en torno a identidades culturales. Eso significaba que el conflicto social se estaba trasladando desde lo económico a «lo cultural», pues cada vez más sería el conocimiento el factor de estructuración social (Bell, 1976), y la cultura el eje de la lucha por la historicidad (Touraine, 1971).

En las décadas de los ochenta y noventa, cuando la revolución tecnológico-informática se instala como eje del capitalismo financiero transnacional, el desempleo estructural se profundiza en gran parte del mundo y luego caen los «socialismos reales», cobraron fuerza nuevas teorías que hablaban de una sociedad que ya definitivamente despegaba su base del trabajo. El núcleo común de las teorías sobre el fin del trabajo es que la automatización de los procesos productivos, la expansión de la economía de servicios y el aumento del desempleo no sólo cuestionaban el concepto moderno de trabajo, sino que le quitaban también su centralidad en la producción de vínculos sociales y valores culturales 
(cf. Offe, 1985; Méda, 1995). Las versiones más optimistas vieron en este escenario la superación de la sociedad salarial. Si ahora las máquinas eran los verdaderos agentes productivos, si cada vez menos personas estaban sometidas a las penurias inherentes al trabajo, si quienes trabajaban lo hacían menos tiempo, ${ }^{4}$ y si las nuevas estrategias empresariales reemplazaban las identidades de clase por las «identidades de empresa» (Gorz, 1998), entonces se abría un espacio para construir una nueva forma de organización social que descansara en identidades y valores liberados del trabajo. La sociedad fundada en el paradigma cultural del trabajo era una construcción histórica, no la expresión de una esencia (Méda, 1995). Pretender, entonces, que el trabajo siguiera siendo la única fuente para establecer lazos sociales, para definir valores comunes e incluso alcanzar estatus, equivalía a seguir sometiendo el vínculo social a relaciones mercantiles en desmedro de relaciones comunitarias y comunicativas, o de actividades realmente realizadoras de la condición humana fundamental: la de homo politicus. Los problemas del desempleo y la subsistencia se podrían resolver ampliando un «tercer sector» de servicios sociales y comunitarios, incluso voluntarios (cf. Rifkin, 1996), o reduciendo los tiempos de trabajo necesarios para satisfacer las necesidades materiales y garantizar un ingreso de existencia que dieran el tiempo y las condiciones para liberar la vida y la creatividad (cf. Gorz, 1998). ${ }^{5}$

La difusión de estas teorías tuvo la virtud de reponer la discusión sobre el trabajo como un tema clave para las sociedades contemporáneas, aunque el desarrollo de esa misma discusión fue revelando la inconsistencia de varios de sus supuestos. Las críticas más articuladas provienen del pensamiento marxista, que bien comparte la utopía de la superación de la sociedad salarial y liberación del trabajo, pero cuestiona por apresuradas y sin fundamento las hipótesis algo ilusas o románticas sobre el advenimiento pleno de una sociedad ya liberada. Románticas porque creyeron que la reducción de la cantidad personas que trabajan en la industria y la cada vez mayor cantidad de personas que tienen

4 La disminución de los tiempos de trabajo había sido uno de los mayores triunfos constante a lo largo de todo el proceso A mediados del siglo pasado el promedio mundial de horas trabajadas para un obrero era de 5.000 horas al año, en los inicios del presente siglo era de 3.200 horas de trabajo, en los años setenta la media era de 1.900 y en la actualidad se ha bajado a 1.520 horas en promedio (Riquelme, 1999).

5 Para una discusión más detallada sobre las distintas teorías que hablan sobre el fin del trabajo, ver Neffa, 2001; Collin, 1998. 
como actividad servicios personales o comunitarios del «tercer sector» reflejaban un avance hacia la reducción del trabajo, sin darse cuenta que lo que en fondo produce es someter a relaciones mercantiles esferas de la vida que antes le eran ajenas y que es justamente lo que se quisiera evitar. ${ }^{6}$ Lo de ilusas es por un error conceptual: confundir trabajo con empleo asalariado en su formato fordista. Resulta innegable que en las últimas décadas se ha reducido el trabajo relativamente estable y bien remunerado de la industria y la administración pública característicos de las «tres décadas de oro del capitalismo industrial»; tampoco se puede negar que la tecnologización de los procesos productivos ha reducido los tiempos y la cantidad de trabajadores que ocupa la producción, pero ninguna de estas condiciones es suficiente para hablar de una sociedad que se estructura por fuera del trabajo. Primero porque el trabajo, como actividad, es un principio antropológico inherente a la especie humana: como ser biológico, su sobrevivencia depende y seguirá dependiendo de la relación que establezca con la naturaleza. Por lo mismo, más que una superación del trabajo, lo que se produce es un cambio de significados, algo esperable si se asume que los significados son construcciones sociales sujetas a relaciones de poder (De la Garza, 2002). Segundo, porque el trabajo asalariado que se supone en retroceso sigue siendo la condición laboral más extendida en todo el mundo. Como ironiza De la Garza, la clase que «vive sólo de jugar en las bolsas de valores» o, como Bourdieu, la clase que «tiene tiempo para perder el tiempo», son una porción sumamente reducida de la población mundial. Para el resto, la mayor parte de los habitantes del planeta, el trabajo asalariado sigue siendo el principal medio de subsistencia y la principal actividad diaria.

Tampoco es totalmente cierta la hipótesis que plantea el definitivo traspaso del trabajo a los circuitos tecnológicos. Los robots redujeron la cantidad de trabajadores, pero engrosaron el desempleo y la informalidad. Tampoco han reducido los tiempos de trabajo. Al contrario, en muchos casos incluso han aumentado. La distribución flexible de los tiempos crea la impresión de menos tiempo de trabajo, pero las «nuevas formas de contratación» que adoptan las empresas imponen condiciones flexibles - trabajos por comisión o sujetos a metasque amarran el salario a un aumento de los tiempos de trabajo. ${ }^{7} \mathrm{La}$

6 Servicios como el cuidado de ancianos o los jardines infantiles, por ejemplo, se expanden por ámbitos que antes cumplía la familia.

7 Los datos muestran que la mayor parte de quienes conforman esta categoría de trabajo son trabajadores no calificados que se desempeñan en 
tendencia también alcanza a los profesionales liberales, que en teoría se podrían dar mayores grados de libertad para disponer de su tiempo, pero muchas veces intensifican sus horas de trabajo hasta superar las jornadas legales. ${ }^{8}$ En definitiva: para toda la-clase-que-vive-deltrabajo se hace insostenible la tesis sobre una subjetividad separada del trabajo. Quienes han venido trabajando las teorías del trabajo inmaterial explican cómo las exigencias de la «producción flexible» postfordista exige a los trabajadores adecuarse a las «demandas del mercado», ser polivalentes funcionales, estar preparados para manejar códigos y señales en vez de habilidades corporales cultivadas por la repetición Todo eso atrapa completamente la subjetividad, involucra al sujeto en sí, absorbe sus conocimientos, sus capacidades lingüística, comunicativa, de interacción, trabajo en equipo, etc., y al hacerla exigencia permanente, de preparación constante, borra la frontera entre tiempos de trabajo y no-trabajo (Virno, 2003). Algo similar ocurre con las nuevas formas de trabajo que se expanden con los avances informáticos, presentadas como formas liberadas de trabajo autogestionado, pero que más calzan con estrategias de las empresas para reducir los costos de inversión en tecnología y el gasto por relaciones formales de trabajo. Es la idea de Huws, que llama cyberproletariado al trabajo de programadores, teletrabajadores y otras modalidades vinculadas a la industria informática (Huws, 2003).

La crítica marxista también cuestiona las versiones sobre la invalidez de la teoría del valor-trabajo. En este punto los argumentos se dirigen a dos objetivos: a la hipótesis sobre el descentramiento del trabajo como fuente de valores culturales e identitarios; y a la teoría neoclásica sobre el valor. En el primer caso, el blanco es la hipótesis de las teorías sobre el fin del trabajo que hace desaparecer la identidad obrera. El contra argumento de los marxistas dice que si la clase trabajadora pareciera haber perdido su identidad, es más por efecto de las nuevas formas de organización empresarial - especialización flexible, separación de unidades, outsourcing, subcontratación-, intencionadamente adoptadas para controlar los espacios en que pudieran fraguar

labores menores de los servicios financieros, la mayoría sin protección y con un promedio de ingresos relativamente bajo (Casen, 2003).

8 Varios estudios sobre las condiciones de trabajo de los cuadros gerenciales revela sus estresantes condiciones laborales, que aunque se trate por lo general de ejecutivos jóvenes, llegan a tal punto que muchos no alcanzan a soportar la presión y terminan renunciando al cabo de dos o tres años. 
identidades colectivas entre los trabajadores, y no por una reducción numérica de la clase que trabaja para vivir. A eso se agrega otro argumento: la imagen clásica del obrero de la industria pesada, con trabajo estable y sindicalizado, siempre fue una minoría en todas las épocas y pocas veces fue la vanguardia del movimiento obrero (De la Garza, 2002). Por una y otra razón, la identidad de clase trabajadora permanece, fragmentada, pero en potencia. Falta que se sacuda y se active.

Para la defensa del valor-trabajo, se apuntan los dardos hacia la tesis neoclásica del valor. Sus exponentes han elaborado distintas fórmulas para quitarle al trabajo la condición base para el valor de las cosas, trasladándola al comportamiento de los de las libres subjetividades de los individuos, sea por la fuerza de la necesidad - la tasa de utilidad marginal—, sea por efectos de distinción social. Con ese giro pretenden superada la teoría del plusvalor. Su error, sin embargo, es que olvidan que los comportamientos de los individuos en el mercado, sus pautas de consumo o los símbolos de distinción, son cargados intencionalmente de simbolismos, pero para producir esos efectos, se requiere el tiempo de trabajo de técnicos, diseñadores, publicistas, etc. (cf. De la Garza, 2002). Por eso el trabajo sigue siendo la base del valor. Incluso más: la cadena de trabajos que agrega valor simbólico a las mercancías, e incluso también las operaciones del sector financiero, son imposibles sin computadoras, cableado, satélites, etc., cuya producción, finalmente, también requiere trabajo. ${ }^{9}$

Para la crítica latinoamericana, las teorías sobre el fin del trabajo tienen, además, una falla de origen: su marcado sello eurocéntrico. Concientemente o no, sus defensores hicieron extensivos los procesos de los países «del centro» o «del norte» —en donde sí se podía hablar de economías industrializadas con Estados sociales relativamente consolidados y un pleno empleo relativamente estable-, a la realidad de países latinoamericanos en que las políticas desarrollistas habían quedado a medio desarrollar y los sistemas de protección social nunca superaron los límites estructurales para su financiamiento. Visto desde esta parte del mundo, lo que ha arrastrado la globalización económica es una reorganización del trabajo a nivel planetario, lo que Antunes

9 Por ahí se entiende la paradoja de la actual fase del capitalismo: intenta hacer creer que la riqueza viene de un sector especulativo que no necesita fuerza de trabajo, pero entra en crisis justamente cuando los volúmenes de circulación de capital financiero se separan de la producción, de la «economía real» (De la Garza, 2006). 
define como nueva morfología del trabajo (Antunes, 2000), en que coexisten sectores altamente productivos, insertos en las estructuras del mercado internacional, pero de una capacidad de generación de puestos de trabajo sumamente reducida, con sectores de baja productividad que no traspasan las economías locales, los bajos sueldos y la precariedad, pero que concentran a cerca de tres cuartas partes del empleo. Esta nueva morfología se reproduce tanto al interior de cada sociedad como a nivel internacional, con divisiones de clase intra e inter sociedades. Ella es la verdadera fuente de la crisis del trabajo. Es la que ha precarizado las condiciones de trabajo, desestructurado las trayectorias laborales y reducido la capacidad de integración social de una gran masa de desempleados y subempleados. Su base está en la reducción de las relaciones de trabajo estables (Castel, 1997). El diagnóstico es claro: los empleos indefinidos son cada vez más escasos, y cuando existen, no aseguran estabilidad ni a mediano ni a largo plazo. ${ }^{10}$ El trabajo deja de ser ese «huso seguro en el cual enrollar y fijar definiciones del yo, identidades y proyectos de vida» (Baumann, 2003:149). Lo que agrava la ruptura es que el trabajo sigue al centro de la construcción de la subjetividad y la identidad de los sujetos. Ya en un estudio realizado en 1987 en varios países europeos se observa que la representación del trabajo es la de un derecho humano fundamental (cf. Meaning of Work, 1987). Las reacciones de descontento de quienes no tienen trabajo o que viven permanentemente en los límites de la exclusión, demuestran que el trabajo "sigue siendo una referencia no solo económica, sino psicológica, cultural y simbólicamente dominante» (Castel, 1997:454). Más que el descentramiento del trabajo, lo que se produce son adaptaciones a sus nuevas lógicas de funcionamiento, lo que Sennet interpretó como las corrosiones del carácter que arrastra su nueva organización (Sennet, 2000) o la nueva cultura del capitalismo (cf. Boltanski y Chiapello, 2002).

\section{TRABAJO Y JUVENTUD}

El efecto de todos estos procesos de transformación del trabajo se expresan sobremanera en las generaciones jóvenes. Varios de los es-

10 Datos de la última Encuesta Laboral en Chile muestran que la mitad de los contratos de los trabajadores tenía duración indefinida, pero no duraban más de tres años en su empleo y una de cada cinco personas termina su contrato en el primer año de vigencia (Encla, 2008). 
tudios que han explorado las transformaciones culturales del nuevo capitalismo lo han hecho mediante comparaciones generacionales. ${ }^{11}$ Para los estudios laborales y los estudios de juventud, las significaciones del trabajo que construyen los jóvenes pasan a representar una puerta de entrada para entender las transformaciones sociales y culturales arrastradas por el nuevo orden que produjeron del trabajo. El enunciado tiene su lógica en la estrecha relación entre trabajo y juventud. Como etapa de la vida y categoría social, la juventud fue un producto intencionado de la sociedad capitalista industrial, un período políticamente inducido e institucionalmente regulado en que se prepara a las sucesivas generaciones para que asuman las múltiples funciones del aparato productivo y de la administración del Estado. ${ }^{12}$ De ahí se entiende el impacto que tienen las transformaciones del trabajo en la producción social de juventudes. No es casual que parte importante de los estudios europeos sobre juventud se concentren precisamente en las

11 El estudio de James Petras sobre los impactos la liberalización económica española y la reforma del Estatuto de Trabajadores en tiempos del PSOE de Felipe González hace una comparación generacional entre padres e hijos de clase obrera y muestra cómo su desafiliación social y política o sus prácticas culturales tiene como fuente las transformaciones estructurales y jurídicas del trabajo (Petras, 1996). El estudio de Richard Sennet sobre la corrosión del carácter provocada por la nueva fase del capitalismo también hace un contrapunto generacional entre miembros de una misma familia (Sennet, 2000). Más recientemente, en Chile, Wolff estudió los efectos de las transformaciones del trabajo en la identidad de los trabajadores del Banco del Estado - hoy BancoEstado- y encontró que los trabajadores que se sienten cómodos con los cambios en los modelos de gestión del trabajo en el mundo financiero - salarios variables ajustados al volumen individual de ventas, comisión por metas, fragmentación interna entre equipos o departamentos de trabajadores, entre otros - son, en su mayoría, empleados y ejecutivos jóvenes que pasan a representar el «tipo de trabajador» que encarna y, de alguna manera, también produce las tensiones que afectan la identidad de los grupos de trabajadores más antiguos que vivieron los cambios organizativos del banco (Wolff, 2005).

12 Abad lo explica como sigue: «La concepción de la juventud como etapa de transición para la etapa adulta y el diseño de las instituciones que regulan su incorporación a la sociedad adulta, no surgieron del proletariado ni fueron una conquista de la Ilustración, sino un resultado políticamente inducido por la burguesía en su conjunto, ante las necesidades del modo de producción capitalista» (Abad, 2005). 
nuevas formas de «ser joven» que produjeron las transformaciones de la sociedad industrial. ${ }^{13}$ Procesos que en el marco de los Estados benefactores y las políticas de «pleno empleo» corrían por canales establecidos y socialmente regulados, con vías de integración claras entre la escuela y el trabajo, fueron perdiendo eficacia y han venido haciendo más dispersos, con formas más irregulares, no tan lineales y más alargadas.

Una serie de estudios sobre la inserción laboral de los jóvenes (We1ler, 2007), y el tránsito entre la escuela y el trabajo (Fawcett, 2002; De Moura, Castro, Carnoy y Wolf, 2000; Casal, 2006) revelan que los títulos escolares, que fueran mecanismo fundamentales para producir una integración laboral relativamente segura, ahora lo hacen sólo parcialmente. ${ }^{14}$ Las «ventajas comparativas» que supuestamente iban a tener las nuevas generaciones más escolarizadas e informatizadas no eran tal (Weller, 2007). Las empresas siguen prefiriendo a trabajadores antiguos o con experiencia, y eso atrapa en un círculo a los jóvenes: le piden una experiencia laboral que es imposible si no se trabaja. Por eso muchos jóvenes trabajan sólo esporádicamente y en empleos precarios, o va y

13 El Instituto de Juventud español ha dedicado números completos de su revista a estudios sobre estas transformaciones en la juventud española y europea en general. Ver en particular Revista de Estudios sobre Juventud $\mathrm{N}^{\mathrm{o}} 56,58$ y 71 .

14 Todos los datos muestran que la formación profesional tiene efectos positivos en la inserción laboral exitosa - por ahí se entiende que las familias chilenas inviertan capital económico en la formación terciaria de sus hijos-, sin embargo hay un factor estructural que es clave: la mayor parte de las economías latinoamericanas genera puestos de trabajo que no necesitan una alta calificación. Los grupos altamente calificados en los sectores más avanzados en conocimiento tienen facilidades para lograr empleos bien remunerados en su campo profesional, pero el efecto reproductor del sistema escolar se los reserva a las generaciones jóvenes de las clases más acomodadas e históricamente más escolarizadas. Por lo mismo, las fracciones cada vez más amplias de las clases medias y los sectores obreros y populares que han pasado a concentrar sus apuestas en la escolarización, corren el serio riesgo de hacerlo sólo para retrasar el paso a un empleo que se anticipa inseguro y precario. Incluso en casos de trayectorias escolares que escapan a ese efecto de «trayectoria colectiva» (cf. Bourdieu, 1989), operan determinantes sociales que limitan el efecto de la escolaridad: la selección de los mejores puestos en las empresas privadas funcionan más por lógicas de reproducción social de las clases dominantes que por criterios estrictamente meritocráticos (cf. Núñez y Ramírez, 2004). 
vuelve de la tasa de desempleo. ${ }^{15}$ Son tendencias que se repiten en todo el mundo. No fue por antojo que una de las figuras con que Castel expuso los efectos de las transformaciones de la sociedad salarial sean precisamente los jóvenes, paradigma de los supernumerarios que produce la nueva cuestión social (cf. Castel, 1997). Para las nuevas generaciones, lo que en el fondo se reduce son las posibilidades de movilidad social por medio de la actividad laboral. Los sistemas que aseguraban la inserción en empleos estables y la proyección de una movilidad social ascendente se han reemplazado por situaciones de precariedad que hacen sumamente difícil que los jóvenes, sobre todo los menos calificados, encuentren empleos que les permitan superar la condición laboral de sus padres (Esping-Andersen). ${ }^{16}$ Más que «movilidad ascendente» entre generaciones, lo que se produce son conversiones ocupacionales, cambios de rama de actividad a otra y curvas de movilidad con ascensos y descensos zigzagueantes (Espinoza, 2006). Eso pasa porque para parte importante de la juventud, la experiencia del trabajo-basura, de la «pega chica» chilena, que antes pudo funcionar como primer contacto con el mundo del trabajo, deja de ser «formación en el trabajo y para el trabajo» y pasa a convertirse en condición permanente. Ahí se entrampa cualquier proyecto de vida de mediano o largo plazo y se terminan eternizando la conformación de sujetos autónomos. Condiciones de independencia, autonomía económica y residencial, acceso a vivienda, formación de pareja y familia, son procesos que las actuales generaciones jóvenes postergan o derechamente evaden. La juventud no se termina de cerrar porque se anula uno de sus componentes: ya no se puede hablar de un período de transición a la adultez, porque la «plena inserción» a la vida productiva se vuelve una meta difusa (Agulló, 1997). Por eso se alargan las trayectorias de vida, y al mantenerse como patrón temporalmente estable, la condición juvenil se extiende «juvenilizando» también a las sucesivas generaciones adultas (Abad, 2005).

15 La situación del desempleo juvenil en Chile no tiene mayores particularidades y a lo largo de los años se mantiene en cerca del $20 \%$, triplicando siempre las tasas de desempleo adulto, muy similar a lo que se observa en el resto del mundo (Reinecke y Veloso, 2005). Pero peor aún: según datos de la OIT, la tasa de informalidad entre los jóvenes incluso supera la de desempleo juvenil (OIT, 2007).

16 Los estudios sobre movilidad intergeneracional en Chile han demostrado que en términos comparativos, si bien hubo una leve tendencia al alza en la década de los noventa, presenta estructuras que la hacen sumamente estática (cf. Núñez y Riesco, 2004). 
Lo anterior es fundamental para entender el supuesto «descentramiento» del trabajo en la subjetividad de las nuevas generaciones. Algunas teorías que circularon durante los años ochenta diagnosticaron una «alergia juvenil al trabajo» que explicaba los aumentos del paro juvenil y la pérdida de peso del trabajo en la vida de las nuevas generaciones de jóvenes (cf. Rousselet, 1974). El desempleo respondía a las elevadas exigencias laborales de los jóvenes, a su reticencia frente a la disciplina laboral y a su escasa motivación por el trabajo. Era autoexclusión (Sanchís, 1988). Sin embargo, los numerosos estudios que han tratado de explorar la subjetividad de las trayectorias de vida (Jacinto et al., 2002; Sepúlveda, 2006) han hecho análisis más complejos que revelan las bases estructurales de las trayectorias. Su irregularidad no responde a ninguna «reacción alérgica» al trabajo, sino que expresa los ajustes subjetivos ligados a las nuevas condiciones que impone el capital al trabajo. Las rupturas en el plano de las significaciones solamente confirman que los significados del trabajo no son estáticos, ni siquiera en el curso de las trayectorias vitales de un mismo sujeto. El para qué de trabajar tiene una dialéctica propia: se va construyendo en la medida que se acumulan experiencias laborales - incluso fallidas o poco exitosas - o por otros cambios en las situaciones que van modificando el lugar del trabajo en las estrategias de vida (Jacinto et al., 2002; Gracia et al., 2001). Por eso es fundamental seguir escarbando en la conversación de los jóvenes sobre el trabajo: es una buena forma de entender las estrategias que se usan para resolver los desafíos de la transición y para captar las nuevas pautas culturales que produce la reorganización del trabajo.

\section{LA CONVERSACIÓN SOBRE EL TRABAJO: TENSIONES Y BÚSQUEDAS}

En lo que sigue se exponen algunos de los puntos más recurrentes en la conversación que producen jóvenes sobre el trabajo. El propósito de esta parte del artículo es contribuir a la discusión sobre el trabajo y la juventud con material empírico. En este caso particular, se exponen los discursos sobre el trabajo que producen jóvenes urbanos de sectores medios y medio-bajo que se encuentran en las etapas teóricamente terminales de la juventud (25-29 años). ${ }^{17}$

17 Uno de los problemas implícitos a cualquier propuesta de trabajar con jóvenes de «sectores medios» o «clase media» es definir los límites de los grupos. La clasificación que hace la encuesta nacional de la juventud per- 
El análisis es sobre el registro de conversación que produjo una serie de grupos de discusión. Los grupos se realizaron en las tres principales ciudades de Chile: Santiago, Valparaíso y Concepción. El análisis muestra los temas que estructuran la conversación y los discursos que se ponen en juego. Los discursos están marcados por los tiempos vitales de los sujetos: están en una etapa en que la segunda década se acerca al final, símbolo de que se acaba el tiempo para probar suerte y se acerca el momento de cerrar la definición de los destinos posibles. Esa condición vital es determinante. Se estrechan los márgenes temporales para «jugar nuevas cartas» y en el caso de quienes tienen hijos, se reducen también los márgenes de libertad de movimiento.

\section{a) La máquina y los engranajes}

Los discursos sobre el trabajo se enmarcan en un contexto. Las figuras de la máquina y los engranajes definen el contexto y describen la condición de los sujetos. La máquina no se nombra solamente como remembranza de la figura paradigmática de la sociedad industrial. Es más que eso. Simboliza al sistema productivo, pero también los problemas diarios de la subsistencia, la alimentación, el pago de la vivienda: es la máquina que pilla, que alcanza y amenaza con arrollar.

La relación con esta máquina es compleja. Como ente abstracto, es autónoma en su funcionamiento. No necesita sujetos. Pero si no se entra en su dinámica, se corre el riesgo de quedar fuera. Las «filas de postulantes» y el «ejército de reserva» que respira al oído recuerdan la fragilidad de los puestos de trabajo y refuerzan la sensación de prescindencia.

Los empresarios no se van a calentar porque...

- Si no estai tú viene otro atrás y les sirve igual. Es un mero costo (Grupo Concepción).

mite un perfil aproximado: los jóvenes de segmentos socioeconómicos medio-bajo y bajo son principalmente hijos de empleados administrativos del sector público y la empresa privada, de vendedores y secretarias, pocos de profesionales y técnicos, varios de obreros calificados y no calificados, de pequeños comerciantes y dueñas de casa. La diferencia entre ambos sectores las define el peso relativo de algunas categorías, especialmente de los profesionales y técnicos, que son más entre los sectores medios, y de los obreros calificados y no calificados, que son más en el sector medio-bajo. 
La máquina sigue sin detenerse y no se detiene a recoger heridos por el camino. Los tiempos de solidaridad entre trabajadores forman parte de un pasado casi mítico. Ahora «cada uno la ve por uno no más». La lógica de la competencia se siente y presiona. Por lo mismo, se impone una lógica de acción individual que pasa por desarrollar estrategias individuales, prepararse, autoagenciarse, aprender a «venderse». También echar mano a los recursos disponibles. La red de contactos - el «capital social»— es uno de ellos, aunque encierra contradicciones: su legitimidad está cuestionada y su alcance es limitado. Ilegítimo porque omite el criterio meritocrático; por eso también es contraproducente: impide conocer el «real valor» personal. Y limitado, no tanto por su ausencia, sino porque las redes son planas, recursivas, dan vueltas en un mismo nivel y no ascienden.

Si al final de cuentas somos hijos de vecino... Soy el primer profesional de mi familia, incluyendo la de mi mamá y la de mi papá. El primero. O sea, no tengo ningún familiar a quien recurrir y decirle... Entonces... ¡Y uno está cagao! (Hombre Grupo C, Concepción).

Los estudios son el otro referente para ocupar un puesto, quizá el más inmediato y nombrado. El funcionamiento de la máquina pareciera producir una especie de «fuerza» que obliga a una educación compulsiva que se asume, pero que no siempre se quiere y que por eso termina produciendo una sensación de agobio y añoranza por tiempos pasados: antes no era necesario estudiar tanto para «surgir» o llevar una vida de «clase media».

Me hubiese gustado haber nacido, no sé, sesenta años atrás. A lo mejor ahí no hubiese tenido la necesidad de estudiar, y hubiese entrado como ayudante, no sé, a Petrox, a Huachipato, y ahí hubiese podido hacer carrera y hoy día hubiese tenido una tremenda casa, mis hijos hubiesen podido estudiar en el Colegio Concepción, no sé (Grupo Hombres, Concepción).

Pero quizá más importante, el desarrollo de la discusión va instalando dudas sobre la veracidad del tópico. Primero, porque la asociación entre estudios y dinero y las historias de intentos negados o carreras truncadas por problemas económicos, son experiencias habituales que se instalan como marco de posibilidades. ${ }^{18}$ Segundo, porque el discur-

18 Diversos informes muestran que el sistema de educación chileno es uno de los más privatizados del mundo, sobre todo en la educación superior (cf. Brunner et al., 2005). 
so escolar se debilita cuando aparece la figura del «cesante ilustrado». El fantasma del profesional joven que no encuentra trabajo o que trabaja en algo diferente a sus estudios le quita legitimidad al título profesional. Incluso en cierta medida puede llegar a convertirse en un límite: los estudios concentran las apuestas en un solo campo.

Hay muchos profesionales que estudiaron cinco años y todo lo demás, y quieren buscar pega en lo que estudiaron, habiendo otros trabajos que no estudiaron, que les pueden dar ingresos, pero ellos como salieron de la universidad, les enseñaron a hacer eso, eso, ¿me entiendes?, se encierran en eso y caen en eso y muchos caen, por ejemplo, en depresión por no encontrar la pega que ellos quieren, saliendo de profesional (Mujer, Valparaíso).

Por eso al final se terminan nivelando las diferencias que pudiera haber entre quienes han seguido una trayectoria de estudios profesionales y quienes han desarrollado su trayectoria en un campo laboral, entre los profesionales por título y los profesionales por oficio. El problema para ambos grupos es que el discurso habla de una sensación sobre la falta de espacio para nuevos engranajes. Los campos profesionales, por ejemplo, están copados por adultos. En la empresa, los adultos explotan y discriminan al trabajador joven. Todo complota contra la posibilidad de posicionarse laboralmente, de abrirse un espacio, de ser un aporte, y de hacer del trabajo una actividad con sentido tanto personal como social: la dimensión social del trabajo no desaparece.

\section{b) Trabajo: entre lo ideal y lo posible}

Una de las interrogantes que abrieron las transformaciones en el mundo del trabajo fue la pregunta por su significado. Las reflexiones de las teorías sobre el fin del trabajo tratan justamente este punto. La conversación grupal lo replantea. Independiente de las palabras con que se nombre, el trabajo tiene una carga ontológica ineludible: está al centro del problema del sentido de vida. Representa uno de los ejes centrales para la realización personal. Todos identifican una actividad que «llena», que «es lo de uno». Pero ahí aparece un primer dilema: llamarlas o no trabajo.

Tú te puedes ganar la vida teniendo un trabajo, pero también hay cosas que pueden no ser remuneradas, pero siguen siendo trabajo, y que tiene que ver con algunas actividades paralelas que uno puede desarrollar y que no necesariamente son remuneradas, pero sí son, para mí, son trabajo (Hombre, Santiago). 
En los grupos de discusión se produjo siempre un momento en que se instalaba la pregunta por la frontera entre lo que es o no trabajo. La duda queda abierta por el otro componente que es básico en la definición del trabajo: su función como medio de reproducción y supervivencia. Aquí el eje es la relación trabajo-dinero: sin trabajo no hay dinero, y sin dinero no hay supervivencia. La discusión sobre el trabajo se mueve entre estos dos planos. Entre lo ontológico y lo pragmático adquiere el doble sentido que lo define. El trabajo ideal es eso: una actividad que realice y dé para vivir. Ambas dimensiones finalmente se terminan fundiendo en un discurso común: no hay realización personal sin bienestar material. Fundir esa dualidad en una sola actividad configura la problemática central de la pregunta por el trabajo. Lo complejo es que ya sea por experiencias ajenas o propias, la idea de «vivir de lo que a uno le gusta» se hace una posibilidad esquiva. Por eso la conversación sobre este punto termina en utopía negada.

Si todos trabajáramos en un trabajo que nos guste el mundo sería perfecto, y nunca va a ser así (Hombre, Santiago).

Lo que queda en medio de esta relación es la condición de realidad, el campo de posibilidades. La presencia de una realidad pone límites, si no absolutos, al menos temporales. Para resolver el nudo se formulan diferentes salidas discursivas. Ninguna se impone como salida única. Por un lado, hay un discurso que sacrifica total o temporalmente la parte ontológica del trabajo y se contenta con la actividad y el salario. Este discurso es más habitual entre quienes lograron hacerse de un «puesto» y sacrifican el gusto por el trabajo a favor del salario, que por lo general se asocia a quienes no tienen estudios de nivel superior.

Yo me veo ahí. No es como que tenga sueños, sino que me veo ahí, no tengo como otra, como surgir. No. Seguir ahí. Igual en lo personal tener mi casa, tener hijos, mi familia, pero yo me veo ahí, como que estoy tan contenta ahí (Mujer Grupo D, Santiago).

Otra desemboca en una relación «instrumental» con el trabajo. Ante la separación entre lo que les gustaría hacer y la necesidad de supervivencia, se sacrifica la primera parte de la ecuación y se privilegia el dinero, que a fin de cuentas es más apremiante. Por eso no importa de qué trabajo se trate, y por eso también la apertura a transitar por empleos de distinto tipo. De hecho la rotación ha sido un elemento común en las tra- 
yectorias laborales de los jóvenes de estos sectores y en muchos casos responde a una búsqueda resignada que privilegia el dinero ante la clausura temporal o definitiva de la realización personal en el trabajo.

Para mí, mi ideal de trabajo es amar lo que uno hace, y lamentablemente me he visto envuelta en varias cosas que no amo, pero que tengo que hacerlas igual (Mujer, Santiago).

No sé, uno tiene que darle no más. Uno en este mundo necesita plata, tiene que hacer lo que sea si no tiene plata (Mujer, Valparaíso).

Para quienes han transitado ligados al trabajo, que no tienen estudios superiores y que ya no piensan o no pueden iniciar ese proceso, la búsqueda de un «buen trabajo» se asocia más a condiciones laborales genéricas que satisfagan sus expectativas. También es importante que el trabajo no sea «aburrido», que no sea tiempo perdido, que en cierta medida se convierte en los últimos depósitos para que el trabajo o, incluso, la existencia, no pierdan todo su sentido.

Yo renuncié al trabajo porque estaba todo el día ahí sentada, ¡no sonaba ni el teléfono! (Mujer, Concepción).

Pero lo más característico en este discurso es que, sea por resignación o por una evaluación realista de su situación, el logro de un buen pasar económico se termina convirtiendo también en fuente de realización personal, porque representa la valoración que los otros hacen de su trabajo y de ellos mismos. El ascenso o el aumento de los ingresos son dos formas en que se expresa este valor, que de paso permitiría sacrificar en parte el gusto por la actividad, que de todos modos, como en el matrimonio a la antigua, el amor puede llegar con el tiempo, y se puede construir subjetivamente sea por acostumbramiento a la actividad, por la construcción de lazos afectivos - los compañeros, el ambiente-, o por una rutinización de la vida cotidiana, que al menos protege de la incertidumbre.

Otra estrategia discursiva privilegia la dimensión ontológica del trabajo, por lo general más frecuente entre jóvenes que tienen estudios profesionales. De ahí se entiende la importancia que adquiere la continuidad de sentido entre estudios y trabajo. La importancia del gusto por el trabajo pareciera reflejar que la búsqueda de este equilibrio les ofrece más alternativas. Pueden complementar el trabajo por gusto con otra actividad paralela que cubra la necesidad económica, o buscar otro tipo de trabajo si la necesidad apremia; pero en ambos casos se trata de medidas temporales que implicarían prorrogar el deseo de realización en el 
trabajo y bajar las expectativas para ajustarlas más que nada en términos de los plazos que se asignan para cumplirlas. El problema es que ambas alternativas implican el sacrificio en el presente de una de las partes de la ecuación, y eso los obliga a gestionar la contradicción entre sus sueños y su situación, con el temor anexo a verse repitiendo la historia de sus padres y tener que «empezar de cero».

Igual a mí mis papás me han comentado que han venido de abajo, pero hoy en día no es así, o sea, mi mamá cuando me dijo «tienes que entrar a estudiar», entra a estudiar ingeniería o algo así, ya te predisponen a que tú tienes que ser más que... ¡más que tus viejos! No ves como lo otro de que tienes que empezar de abajo, no, al'tiro métete a medicina, métete a ingeniería, métete a... me entiendes o no, a las carreras más altas que te permiten llegar a un nivel de vida superior. Entonces, si te predisponen a eso es difícil que tú puedas cambiar el switch, y decir «ya, tengo que empezar de abajo» (Hombre, Concepción).

De todos modos, en el discurso de los profesionales se deja ver una mayor confianza en que van a lograr equilibrar de mejor manera esa balanza en el mediano o en el largo plazo. En cierta medida el hecho de ser profesionales les otorga un margen más amplio para negociar entre «lo que se quiere hacer» y «lo que le piden que haga», de buscar espacios para desarrollar los gustos o los intereses personales dentro de la profesión. Pero más allá de estas diferencias, lo que une ambos discursos es esta búsqueda por combinar la posibilidad de desplegar su «vocación» con la búsqueda de un bienestar económico.

Nadie concibe una vida sin trabajo, porque sin trabajo se corre el riesgo de «no ser nada», que se asocia al desarrollo de las potencialidades individuales, pero también al logro de una posición en la estructura de la sociedad en general, de un campo en particular o de un espacio laboral específico. Lo que es especialmente complejo para un sector de la juventud que se autodefine transitando por una etapa de su existencia en que ya se les vino encima el momento para tomar las grandes decisiones, en que se les acaba el tiempo para «reinventarse», para lograr un «buen trabajo», o más allá todavía, para decidir lo que van a hacer por el resto de la vida. Y eso evidentemente genera angustia y una sensación de incertidumbre que termina produciendo una conversación en la que abundan los «de repente», los «en una de ésas», los «quizá», los «no sé», todas expresiones que dejan el futuro en suspenso. 


\section{c) Juegos de identidad, identidades en juego}

Un tópico que define la construcción discursiva sobre el «mundo del trabajo» es la de un ámbito de acción que tiene sus propios códigos de acceso y lógicas particulares: supone formas típicas de comportamiento conocidas que regulan los códigos tanto en los momentos/lugares de ingreso como en los lugares de trabajo propiamente tales. En ambos momentos lo que se pone en juego es una conversación sobre las posibilidades de desarrollar la propia identidad. La presencia de la figura del «perfil» que piden las empresas, esta especie de «tipo ideal» de trabajador, muchas veces obliga a tener que ajustarse a cómo quieren que sea. Por eso, en cualquiera de sus etapas, la selección aparece como una especie de «juego de imágenes». El currículum, por ejemplo, forma una imagen, y por lo mismo se puede manipular: se puede aumentar, editar, seleccionar la mejor foto, o en su extremo, incluso se puede falsear el currículum o trucar la foto. En las entrevistas personales, se puede manejar la postura corporal, transmitir seguridad, convencer... En los test psicológicos, se pueden manejar técnicas de respuesta para engañar al test y ajustar los resultados. ${ }^{19}$

He escuchado a muchos sobre ese tema de las figuritas, he escuchado que no pongas nunca cosas cochinas, ¡nunca cosas cochinas!

- Todo blanco.

- Claro. Puedes ver un gusano desangrándose, pero tienes que ver una mariposa (Grupo Santiago).

Después en la entrevista, como se dice uno tiene que irse bien convencido uno primero para convencer al que tienes que... a la otra persona. -Tienes que venderla (Grupo Concepción).

La referencia al «venderla» es quizá la más clara muestra: hay que ser lo que no se es, vender una imagen inspirada en el mito del «perfil del

19 En librerías, en internet y hasta en el nuevo portal de información laboral que dispuso el gobierno (www.sil.gov.cl) se pueden encontrar manuales y cursos que enseñan a manejar entrevistas de trabajo. Las recomendaciones van desde la preparación previa, hasta el manejo retórico, kinésico, proxémico e icónico - la vestimenta, la ornamentación, la pintura facial - en la entrevista, lo que de paso refleja la extensión del dominio de las técnicas de la psicología laboral en la selección de personal, sobre todo para el sector servicios. 
trabajador», que puede estar muy vinculado al tipo de trabajos en los que se están moviendo los jóvenes de estos sectores - sector servicios comerciales, vendedores, call center-, pero más allá, es una clara muestra sobre el vaciamiento de significado del trabajo en su forma de empleo: «venderla» es simular que el trabajo interesa cuando en realidad lo importante es el ingreso.

La simulación permite entrar al mundo del trabajo, y se extiende una vez dentro. Pasada la selección, hay que acatar, asumir las normas y los símbolos con que opera el mundo del trabajo, asumir la forma de ser que impone. Esta adaptación representa una ruptura especialmente compleja cuando se es joven. Muchas veces incluye cambios en la estética, en el pelo, en los hábitos y los modos de vestir. Pero también implica la sumisión, o su simulación, que en el fondo refleja el discurso que impone la subordinación.

Es complicado porque de repente para cuidar tu pega es más fácil quedarte ahí, piolita, lo más bajo perfil (Hombre, Concepción).

Hay otra dimensión de la identidad que también es compleja de mantener, aunque se reduzca principalmente a quienes tienen un título que en principio les aseguraría una posición privilegiada en el futuro. En estos casos está el temor a no perder lo que se puede definir como una identidad de clase, de ser fieles a su origen, y no olvidar que «vienen de abajo» cuando supuestamente «estén arriba».

Lo interesante es que la conversación sobre estas estrategias para entrar y mantenerse en el mundo del trabajo, muestran que por todos lados pareciera que la identidad se ve amenazada. Ya sea por la entrada o por la permanencia, se habla de una negación a la posibilidad de ser sí mismos, ser como se quiere ser. No se logra articular un discurso que resuelva esta tensión de mejor manera que transando o simulando. Hay intentos de resistencia parciales, que tienen que ver con la defensa de una estética, o con otros mecanismos para mantener una cuota de autonomía, pero son difíciles de sostener cuando pasa el tiempo y la falta de trabajo empieza a generar problemas, sobre todo para quienes tienen responsabilidades familiares.

En el caso de mi pelo, no me lo cortaría. Pero si ya, no sé, si tengo tres pendejos atrás... Solo, yo no me lo corto. Yo voy a otra pega, y si no, voy a otra, a otra, a otra, hasta que me acepten. Pero si tengo hijos ya es otra cosa, es otra cosa. 
-Es que ahí cuando uno tiene familia ya uno no la ve por uno (Grupo Valparaíso).

Una situación compleja si tenemos en cuenta que el discurso que elaboran en el fondo demanda que se valore «por lo que se es», posiblemente uno de los anhelos más profundos de los jóvenes respecto al mundo del trabajo. Por eso cuando la posibilidad se da, aunque sea excepcional, produce una satisfacción que lleva incluso a transar con las otras dimensiones que debiera cumplir un trabajo ideal.

El ambiente es muy relajado, mis compañeros son muy buena onda, entonces eso lo paga todo. No me pagan muy bien, pero yo estoy relajado, estoy bien, soy yo, no ando fingiendo ser otra persona. Soy yo y me desenvuelvo con naturalidad (Hombre, Valparaíso)

\section{d) Estabilidad, libertad}

La estabilidad laboral es una de las grandes pérdidas que arrastraron las transformaciones del trabajo. Sobre este punto la conversación parte haciendo una constatación: ya no se puede hablar de la estabilidad «de antes». En el actual escenario del trabajo, marcado por la rotación, despidos, ausencia de contratos..., pareciera que incluso ya no se puede hablar de estabilidad.

Es como irreal a veces porque, por lo mismo, tienes contrato pero no lo aplican. Entonces, es muy... ya llega a ser ambiguo en realidad el mismo, la misma palabra. Como que ya no existiera la estabilidad y como que nos hacen creer también que no va a existir estabilidad (Mujer, Santiago).

La conversación va desembocando en una contradicción: por un lado se quiere estabilidad — que es estabilidad de ingresos, pero también estabilidad psicológica y emocional-, pero por otro el discurso deja entrever dispositivos subjetivos que hacen tolerable o incluso aceptable la rotación o el cambio. En primer lugar, porque el paso por diferentes trabajos reporta experiencia. En algunos pasajes se dice que es un plus: el largo del currículum muestra la variedad de habilidades aprendidas, la capacidad de adaptación, el abanico de competencias. En segundo lugar, el cambio de trabajos se formula también como rechazo a la rutina de un trabajo mecanizado que le quita sentido a la actividad. En tercer lugar, la ideología que individualiza el destino laboral y la búsqueda de soluciones individuales a las tensiones subjetivas del trabajo, predispone al tránsito por 
distintos trabajos. En este escenario donde nada es seguro, es mejor estar dispuestos al cambio, lo que en el fondo sería un atributo del sujeto contemporáneo que se expresaría de sobremanera en los jóvenes.

Estamos más dispuestos a movernos, y también tiene que ver con este desligue en general, con este individuo de esta época, que se ha desligado hasta del lugar donde vive, del trabajo que tiene (Hombre, Valparaíso).

El peso de la evidencia obliga a asumir que el cambio de trabajo es una realidad transversal, que atraviesa todos los sectores. Para los profesionales que trabajan por proyecto la rotación es inevitable. Lo mismo para quienes no tienen un oficio definido o los que trabajan por obra: todos están sujetos a cambio. Son las reglas que dominan el mundo del trabajo. Se da por hecho que los trabajos de por vida ya prácticamente no existen. Su propia trayectoria laboral les ha enseñado a convivir con la rotación, a adaptarse a este escenario, en un efecto subjetivo que se expresa cuando la proyección temporal de la vida laboral se figura en ciclos.

A mí me pasa algo parecido. A veces cuando me pienso, me miro, yo espero no estar más de cinco años más acá, para poder pensar en otra pega, en otro lado, y así... pienso en ciclos, pero me cuesta pensarme en esta cosa de la carrera en una sola empresa, o en una sola institución durante años. Cambiar para no acostumbrarse, porque la rutina al final igual te va matando en ese sentido (Grupo Valparaíso).

Figurativamente aquí hay una diferencia. Para quienes tienen títulos profesionales, pareciera que la figura que más se ajusta es la de espirales: el futuro se piensa en ciclos ascendentes que se alimentan de los intereses personales, del cambio o el agotamiento del interés en un trabajo, o incluso de búsquedas existenciales y decisiones personales. Por eso la rotación se vive más como libertad y como crecimiento profesional, como un quemar etapas en una trayectoria ascendente. En el caso de quienes trabajan y no tienen títulos, también se piensa en ciclos, pero más como sucesión de círculos superpuestos, que se abren y cierran por la relación entre «la necesidad» y las relaciones laborales, entre el agrado con el lugar de trabajo y el grado de abusos recibidos, sin espiral ascendente, más fluctuantes y con un techo que limita los componentes del trabajo ideal: el incremento del salario y la realización personal. Pero más allá de la diferencia, en el discurso de ambas situaciones pareciera que el cambio de trabajo se anticipa como 
una decisión del sujeto, con la saturación y la pérdida del interés por la actividad como referentes comunes.

Lo que decías tú es como lo que decía yo un rato atrás. Lo que dices tú, el trabajo, la proyección. A lo mejor no es ganar más dinero, pero no estar constantemente, estar sentada ahí, no, y seguir sentada todo el año, todo el año, todo el año, no. Hay que igual ir cambiando (Mujer, Concepción).

El nudo que se instala es la relación libertad/estabilidad. En primer lugar, condensa los problemas de concretar los proyectos de vida: sin estabilidad, no hay posibilidades para concretarlos, formar una familia, acceder al crédito o la hipoteca...

Igual a mí ya me hubiese gustado ser papá. No me gustaría tener tanta diferencia con un hijo, esperando alguna vez poder carretear con él, y no tener, no sé, setenta, y que el loco tenga veinte, ya no me va a pescar, un viejo gagá. Entonces me gustaría ser joven para poder disfrutar una familia. Hasta el momento no lo he podido hacer porque todavía no, lo que más he durado con contrato, un año, porque después del año te tienen que poner contrato indefinido (Hombre, Concepción).

En segundo lugar, la imposibilidad de resolver adecuadamente la relación entre estas búsquedas de libertad de movimiento y la necesidad financiera. Dejar los trabajos por decisión propia es difícil, requiere un respaldo económico. Es un lujo que parece reducir la alternativa al plano de los discursos y no de las posibilidades, sobre todo cuando ya se tiene familia o se han asumido mayores grados de autonomía. La conversación trata esta dificultad de resolver una postura clara respecto a la estabilidad y cómo definirla. Por un lado anhelan tener el grado de libertad para moverse por el mundo del trabajo y desarrollar los ciclos que acerquen al trabajo que realiza y da para vivir, pero por otro lado también quieren tener una condición de vida estable, que pasa fundamentalmente por lograr un flujo de ingresos que no se interrumpa.

Hay una paradoja porque por un lado anhelamos tener un contrato de trabajo seguro y estable, en un lugar que nos dé derecho a salud, a casa, a educación y que podamos desarrollar, no sé. Pero por otro lado también, yo creo que en algún minuto, también quiero un sentido como más humano o que yo pueda ir modificando los distintos intereses que tengo, a lo mejor trabajar en un lugar menos... o después si me quiero cambiar poder tener esa flexibilidad de tomar la decisión de agarrar mis cosas e irme a otro lugar o trabajar en otra área (Mujer, Valparaíso). 
La dificultad es que solucionar estas tensiones se entiende como un problema básicamente individual. Sea trabajando para acumular un capital de reserva que permita sortear el período de desempleo o por otro mecanismo, no se logra articular otra salida que no sea adoptando una estrategia personal. Es cada uno quien debe resolverlo y eso devuelve la conversación a la idea de la búsqueda de condiciones laborales que brinden mayores garantías. El problema aquí es para quienes ya son independientes, pero sobre todo para quienes tienen mayores cargas de responsabilidad. En estos casos la posibilidad de búsqueda se reduce porque se pierden los márgenes de movimiento.

\section{e) Los dilemas del tiempo}

El tema del tiempo sigue siendo ineludible al hablar de trabajo. Los tópicos de la conversación son similares a las que ha desarrollado la teoría social desde ya hace un buen rato: la relación entre tiempo de trabajo y tiempo de vida. La relación es compleja: trabajar cansa, pero no trabajar le quita sentido al tiempo. El trabajo forma parte de la vida, pero no es la vida, aunque en términos subjetivos, tratar de establecer dónde está esa separación es difícil de verbalizar y explicar racionalmente.

Cuando estoy en la pega lo único que quiero es, no sé, tener mi tiempo para descansar, pero cuando, y a mí me ha pasado, cuando estoy con licencia lo único que quiero es volver a mi pega, de verdad, es una cuestión como... ya es una necesidad.

-Es que ya es parte de ti, tu trabajo es parte de ti.

-A parte que yo ya llevo hartos años trabajando, entonces es por, no es por la plata, es por..., ¡no sé, pues, no sé! (Grupo Mujeres, Concepción).

La conversación no logra resolver del todo este dilema, pero en la medida que se desarrolla. La vida pareciera estar distribuida en dos tiempos: el tiempo de trabajo y el tiempo para la vida. Cuando se trabaja, el tiempo de trabajo cubre la mayor parte del día; por eso la metáfora del «segundo hogar» para referirse al espacio de trabajo, y de «la otra familia» en el caso de los compañeros de trabajo. El tiempo de trabajo le da un sentido de productividad al tiempo, lo haría "provechoso», evita sentir que se pierde el tiempo, sobre todo cuando el trabajo se hace con gusto. El problema es que el hecho de trabajar implica asumir que el tiempo para «la vida» se estrecha y en muchos casos 
significa sacrificar la posibilidad de hacer «otras cosas» o «cosas de jóvenes». De ahí la queja: el trabajo no deja tiempo para vivir. Trabajar obliga a no respetar los ritmos del cuerpo, a andar apurado, impide hacer otras cosas, conversar. Eso ocurre con todos los trabajos. Esas son las fuentes para algunos fantasmas que recorren la conversación: el estrés y la descomposición familiar.

Yo considero que el ser humano aquí en Chile trabaja mucho... Al final hay muchas otras cosas que también son importantes y que tú las tienes que dejar de lado (Mujer, Concepción).

La solución lleva a un lugar común: «trabajar para vivir y no vivir para trabajar». Ese tópico resume el discurso. Lo que complica la solución es el dinero. El peso del trabajo asalariado como mecanismo de subsistencia implica que la relación entre el tiempo de trabajo y el tiempo para la vida queda sujeta al logro de la subsistencia. Ahí se encierra una contradicción.

Yo creo que uno tiene que trabajar para no trabajar.

- Claro, es que tienes que trabajar para no trabajar tantos días. Pero igual tienes que trabajar.

- Tienes que trabajar para poder tener tu tiempo libre (Grupo Valparaíso).

Lo ideal sería que no se tratara de opciones excluyentes, pero las dinámicas actuales del mundo del trabajo, marcadas por la inestabilidad de los empleos, pero sobre todo por el tipo de trabajos a los que acceden los jóvenes de estos sectores, marcados por la regular o escasa valoración económica de los trabajos y por la extensión de los horarios, son factores que complican el equilibrio entre estos dos tiempos. La dificultad para resolver el modo en que quisieran esta dualidad a la larga lo que pone en juego es la concreción de sus proyectos de vida. Al menos en términos discursivos, no pretenden grandes lujos ni esperan entrar al mundo del poder. Y aunque se hace referencia a una especie de escalada progresiva en términos de pautas de consumo o de grados de bienestar, el imaginario para sus aspiraciones es más bien mesocrático y en general apuntan a reproducir las condiciones y el estilo de vida de la clase media, o en su extremo, no perder su actual condición, no «caer». En el plano personal, muchos quieren formar su propia familia, otros ya lo han hecho y aspiran, por ejemplo, a la casa propia; pero esos proyectos «lamentablemente hay que financiarlos», como dicen en un pasaje de la conversación, y ese mismo financiamiento termina poniendo límites a 
los proyectos. Para quienes ya tienen familia, el tiempo de trabajo reduce el tiempo disponible para la vida familiar y produce un contrasentido: se trabaja para mantener la familia, pero no se puede disfrutar de la vida familiar. El fantasma de la descomposición familiar, de la pareja que no se ve o de los hijos que crecen solos representa uno de los riesgos que trae el escenario de trabajo actual, sobre todo en aquellos tipos de trabajo que funcionan en base a metas de productividad o por comisión. Éstos son los que más agudizan la contradicción: por un lado «no estancan en la parte económica», pero por otro traspasan completamente el nivel de ingresos al individuo.

Hay mucha gente que trabaja todo el día, hace horas extras, no ve a sus niños y lo único que le importa es tener más plata para poder seguir en la sociedad que estamos viviendo (Mujer, Valparaíso).

El otro fantasma que recorre la conversación es el estrés. La certeza sobre la mala remuneración de sus trabajos deja pocas alternativas de compensación que no sea la extensión del tiempo de trabajo. Pero cuando el tiempo libre se reduce, el cuerpo se cansa, lo que es más complejo todavía para quienes tienen hijos, porque la responsabilidad familiar acelera el ritmo de vida y no deja tiempo para hacer «otras cosas».

A quien no tiene hijo de repente no tiene la experiencia, pero sí tu cuerpo te pide un descanso, te pide que tú te relajes, que de repente te vayas a tomar un café con tus amigas, y no lo puedes hacer porque miras el reloj y, «ya, son las siete, me voy corriendo, tengo que hacer esto, tengo que hacer lo otro», entonces en general considero que aquí el trabajo te absorbe mucho, y por eso que uno, de repente, «iya, no quiero hacer nada más!», porque los sueldos tampoco, de repente, son altos, entonces tú... ¡te cansas, pues! (Mujer, Concepción).

Por eso mismo para quienes todavía no tienen familia, la idea de formar una propia pierde consistencia. La evidencia sobre las dificultades para financiar los proyectos de vida o los relatos sobre el estrés de quienes tienen hijos, terminan legitimando una disposición que naturaliza la postergación de la familia propia o la autonomía residencial.

Yo creo que la gente de antes se proyectaban más porque querían tener hijos, o porque tenían más hijos y tenían que tener un trabajo para poder alimentarlos, pero ahora los jóvenes ya casi no van por ese lado de querer tener esa familia de tantos hijos (Mujer, Valparaíso). 
Hoy en día no sería necesario «salir del nido» para tener grados de libertad. La conversación da cuenta de un cambio cultural al interior de las familias que otorga mayores grados de negociación de la autonomía sin que sea necesario migrar. Es posible que el dilema en este punto sea más complejo para las mujeres: por un lado quieren posponer la independencia y la conformación de familia propia, pero sienten que cargan con el peso de tener que hacer frente a una especie de presión social implícita que les forzaría a cumplir los «roles tradicionales» de la mujer, los ciclos de las «mujeres normales».

Pero más allá de eso, la tensión que todos tienen que resolver es cómo encontrar un equilibrio entre el dinero y el tiempo para la vida. Sin trabajo no hay dinero, los proyectos personales no se financian, ni tampoco se puede disfrutar del tiempo libre (el consumo de entretención). Pero con trabajo, hay (algo de) dinero, pero tampoco se puede disfrutar el tiempo. Resolver esta ecuación se vuelve un ejercicio individual que devuelve a la idea de la búsqueda. Es cada uno quien tiene que buscar el trabajo que le permita distribuir los tiempos de trabajo y el tiempo de vida de la mejor manera, lo que nuevamente lleva la conversación sobre el trabajo al dilema del sentido de vida.

$\mathrm{Y}$ en ese sentido las proyecciones que uno tiene de trabajo tienen que ver también con este como bombardeo de qué es tener un trabajo, de trabajar cuánto, cinco días a la semana y las otras... y el fin de semana para ti, y al final también llega en un momento a ser como casi angustiante en el sentido que te vas envolviendo en el sistema. Es como la interrogante de qué quiero como vida (Hombre, Valparaíso).

\section{LA BÚSQUEDA DE SALIDAS}

Frente a este conjunto de tensiones que encierra el trabajo, en todos los grupos se escuchan pasajes de la conversación en que se intentan articular soluciones posibles. Toda esta conversación se puede entender como la búsqueda de alternativas para contrarrestar la fuerza de la máquina aceitada, metáfora que simboliza la potencia del sistema neoliberal y la dificultad para pensar en formas alternativas de organización social.

En un momento hablan de cambios estructurales que exigen la intervención del Estado, personificado en el gobierno. El primer papel que se le asigna se dirige a legislar y fiscalizar las denuncias sobre abusos laborales, aunque en la medida que se desarrolla esta idea se va concluyendo que en esos planos el Estado no es prenda de ninguna 
garantía. De hecho, en el discurso se homologan las políticas del Estado con el interés del gran empresariado. Esa es la sospecha que vierten sobre las leyes laborales o los tratados de libre comercio, que son procesos que sienten totalmente ajenos y que miran desde fuera.

Que el gobierno está bien económicamente, eso es para los que tienen, para los que tienen inversiones, que trabajan en la bolsa, los que tienen empresas, pero para uno, uno no lo ve, no lo ve, ese es mi punto de vista. Y yo creo que de la mediana clase para abajo, no la ve. $Y$ tiene que levantarse igual a las cuatro, cinco de la mañana y sacarse la cresta hasta las ocho, nueve de la noche para poder ganar la plata (Hombre, Valparaíso).

La segunda salida que involucra al Estado es en la regulación estatal de las titulaciones. Ante la saturación de los campos laborales, la sobreoferta de titulados en todas las áreas y la devaluación progresiva de los títulos, una salida posible pasaría por una política que regule la libertad con que opera el mercado educacional. El problema es la viabilidad de esta salida, que se termina diluyendo por su propia complejidad y magnitud.

No se cambia de un día para otro, y nosotros yo creo que somos un grano en la playa si queremos cambiar eso (Hombre, Concepción).

Ante esta clausura de las transformaciones estructurales, se ensayan otras estrategias. Una primera alternativa que se explora pasa por generar nuevos modelos de trabajo autónomos donde se puedan implementar formas de trabajo que pongan en práctica códigos de relación laboral cuyo centro no sean ni la productividad ni el capital, sino el sujeto y su bienestar. Se habla de generar experiencias que abran cursos transformadores, que actúen con arreglo a principios de justicia, que incluyan la distribución equitativa de las utilidades, y que se instalen como ejemplos a imitar que puedan transformarse en pautas extensibles en la medida que se legitimen.

Podríamos armar como una nueva estructura de funcionamiento empresarial, que podría respetar ciertos «flujos» que permitan un desarrollo individual. Sería una forma digamos de ir cambiando el sistema (Hombre, Concepción).

A partir de esta solución intentan articular un discurso generacional: se habla de la necesidad de asumir una responsabilidad o una misión histórica. 
No sé, yo pienso que nosotros igual deberíamos demostrar ser distintos y cortar la cadena (Hombre, Concepción).

En otros pasajes se habla de acciones que se reducen a acciones individuales. Una primera modalidad la podríamos definir como una salida «heroica». Ya sea desechando trabajos que no cumplen con las expectativas y las condiciones mínimas esperadas, exigiendo contratos, negándose a cumplir funciones que no estaban contempladas en el acuerdo original, o reclamando los derechos laborales en el lugar de trabajo, se pueden ejercer actos de resistencia parciales sin ninguna otra pretensión que la de marcar pautas o poner límites a los abusos de los empleadores y que tiene a la renuncia como expresión límite.

Estuve tres meses pero no me gustó el trato y me di el gusto de renunciar (Hombre, Valparaíso).

Lo complejo de esta lógica es que es sólo testimonial y no evita que se sigan reproduciendo las lógicas con que opera el mundo del trabajo. Además, el límite último de la renuncia implica asumir el riesgo del desempleo, un paso complejo por definición, sobre todo cuando se tienen cargas de responsabilidad familiar.

Una última solución que se logra esbozar es optar por el desarraigo y migrar en busca de un mejor destino. La otra alternativa es el retiro del mundo urbano y la conversión al agro, en un relato que recuerda las utopías de los sesenta y setenta. Pero al igual que todos estos lugares por los que pasa la conversación en su búsqueda por soluciones, tiene sus límites y termina como una solución parcial. La metáfora de la «máquina aceitada» es tan fuerte que pareciera no dejar espacio para alternativa de transformación.

\section{AlCANCES POSIBLES}

Los cambios en la organización del sistema de trabajo han tenido consecuencias sociales y culturales profundas. De eso no hay duda. La producción social de juventudes es una de sus más claras expresiones. Se observa como tendencias demográficas, trayectorias de vida y construcciones subjetivas. Este texto expone un registro de ese componente subjetivo. Su análisis sugiere que hablar de trabajo condensa las tensiones que encierra la búsqueda de soluciones a los dilemas del sentido de vida y los problemas de la supervivencia. No ser engranajes ni ser prescindi- 
bles, tener un lugar, «aportar con lo de uno», que «hacer lo de uno» permita «ser uno» y ambas condiciones den bien-estar, una vida digna, son todos enunciados que condensan los sentimientos que se producen al estar en una etapa de la vida en que se enfrenta la «máquina aceitada», representación gráfica de un sistema ideológicamente blindado, soportado en andamiajes políticos y jurídicos aparentemente inamovibles que parecieran alejar la posibilidad de bajarle el ritmo, darle una vuelta de tuerca, dominar su movimiento, humanizarla.

Esta «necesidad de tener un lugar» se asemeja a la utopía del «pleno empleo universal» de Jameson. ${ }^{20}$ Pero la discusión de los grupos muestra que el empleo, por sí solo, no alcanza a resolver todas cuestiones del trabajo. Es una parte, la del problema de la actividad remunerada, pero el trabajo es más que empleo. Si se redujera solamente a su forma/empleo, el problema quedaría resuelto con políticas de inserción laboral juvenil, por ejemplo. Pero no es sólo eso, menos si al fondo de estas políticas van ocultas estrategias para instaurar la flexibilidad laboral y controlar los salarios. ${ }^{21}$ El hilo de la discusión parece apuntar a otra parte, más abajo, a las bases y el motor de la máquina o al problema de la organización social del trabajo. Los te-

20 «Si me pregunto — dice Jameson - cuál sería, a día de hoy, la reivindicación más radical que cabría hacer con respecto a nuestro sistema - esa reivindicación que no podría ser respondida o satisfecha sin transformar el sistema hasta hacerlo irreconocible y que a la vez marcaría el comienzo de una sociedad estructuralmente distinta de la actual en todos los sentidos concebibles, desde el psicológico hasta el sociológico, desde el cultural hasta el político - sería la reivindicación del pleno empleo, de un pleno empleo universal en todo el planeta» (Jameson, 2004:1).

21 A modo de ejemplo, el plan de flexibilidad que propuso la Comisión Laboral de la Cámara Chileno Norteamericana de Comercio — encabezada por representantes locales de la General Motors- el año 2006, incluye un programa de empleo dirigido a jóvenes que descansa en una supuesta «reciprocidad entre jóvenes y empresa»: los beneficiados se capacitan y adquieren experiencia y las empresas pueden «contratar fuerza de trabajo menos costosa». La duda queda boteando: ¿por qué «menos costosa»? No se dice, pero se deduce que el criterio es la «menor necesidad» del «tramo etáreo» objetivo (18 a 24 años). El criterio comete dos errores: ignora que muchos jóvenes a esa edad ya tienen responsabilidades familiares que anulan el supuesto; y no asume que cualquier plan dirigido a jóvenes de sectores vulnerables debe restituir la postergación histórica de quienes acumulan más necesidades. 
mas que estructuran la conversación y los discursos son diferentes modulaciones de esa búsqueda. La pregunta sobre el sentido del trabajo plantea dos dilemas fundamentales: la frontera entre trabajo y notrabajo, y la definición de sus componentes. Ambos muestran que el trabajo adquiere sentido cuando la actividad logra resolver la subsistencia. La diferencia entre las estrategias discursivas que se despliegan en este punto depende del lugar donde se deposita el sentido: si es en el salario o en la actividad. Es la tensión que intentaron resolver los discursos. Quienes depositan la realización en el salario, privilegian la urgencia de la reproducción de la vida y el consumo: no importa el empleo si el dinero es bueno. Su versión extrema es la negación consumista: las cosas y el humano convertidos en fetiches. El discurso de la sumisión al trabajo sin sentido, pero estable, es la renuncia a la realización por la actividad. Ambos discursos son soporte para la enajenación del trabajo. Es lo que plantea Gorz: el ingreso como necesidad imperiosa sirve para hacer pasar de contrabando la necesidad imperiosa de trabajar (Gorz, 1996). Por el otro lado, el discurso que deposita el sentido del trabajo en la realización personal o profesional contiene una negación a las lógicas del «mercado de trabajo» que aproxima el sentido del trabajo a su forma de actividad y obra — para tomar los conceptos que usa Méda-, pero tiene un límite en el problema de la subsistencia. Por eso tampoco resuelve el problema del trabajo en el presente: lo deja para el futuro. El riesgo de este discurso es que puede terminar negándose a sí mismo para convertirse — «la necesidad tiene cara de hereje»—; o bien, trasladar la realización negada al tiempo de no-trabajo, con el riesgo de borrar la barrera y hacer coincidir el tiempo de vida con el tiempo de trabajo.

Ningún discurso parece lograr por ahora resolver las dos dimensiones del trabajo. Todos desembocan en una postergación de una de las dos partes de la ecuación. La inevitable transacción con formas de empleo temporales es una tendencia frecuente, pero son soluciones parciales que adquieren sentido casi solamente como experiencias, aprendizajes, pero que desembocan en dos problemas paralelos: la identidad y la estabilidad. Primero porque el predominio de las salidas por la vía de empleos que resuelven parcialmente el salario alimentan esas estrategias de simulación que produce la heteronomía del trabajo. Es un juego perverso, por cierto: permite sortear las barreras de acceso simulando, «vendiéndola», mantenerse empleado «haciendo como que» el trabajo gusta, pero en el fondo no hace más que reforzar la enajenación del trabajo y la asimetría de poderes. Pero la lectura contraria es más optimista: la simulación también es un límite para las técnicas de control empresa- 
rial basadas en lo que Gounet llama el involucramiento cooptado (Gounet, 1999), o el recurso al «sentido de pertenencia». La relación en que descansan es artificial, instrumental, no es genuina.

El segundo problema es la inestabilidad, otra forma en que se expresan las dificultades para lograr equilibrios entre la realización y el salario. La estabilidad es un equilibrio psicológico, un bien-estar en que también se juegan los proyectos de vida y su financiamiento. Este último punto es quizá el más importante: la inestabilidad psicológica es fundamentalmente el efecto subjetivo de la imposibilidad de resolver adecuadamente la base económica de la subsistencia y los proyectos de vida. Su base es empírica: la precariedad económica impide hacer una vida estable, tener un bien-estar..$^{22} \mathrm{Y}$ si se sigue la hebra, se llega a un problema difícil, pero fundamental: la distribución social de la riqueza. Es un tema que se alude con sarcasmos, pero esas mismas estrategias comunicativas muestran que está en la base del problema del trabajo. No es casualidad que en los últimos años ésta haya sido un motivo para la movilización de trabajadores. ${ }^{23} \mathrm{Y}$ se entiende. La lógica del crecimiento y el «chorreo hacia abajo» no han sido más que una cortina de humo. Dejar en manos del mercado la distribución de los beneficios del trabajo colectivo es contradictorio: recuerda la fábula de la rana y el escorpión. Durante estos largos años de libre mercado extremo, Chile no se ha movido del grupo con peor distribución de la riqueza. Es más: si últimamente han disminuido en algo las diferencias de ingreso entre los quintiles extremos, ha sido por efecto de los subsidios públicos auxiliares para los hogares más pobres, no por una reestructuración distributiva del producto social (Reinecke, 2008). Aquí es necesario recordar un principio de economía: que el salario es trabajo de otros hecho signo y materia (Riesco, 1999). Si los problemas del tra-

22 Un estudio de la Universidad Adolfo Ibáñez reveló que uno de cada cuatro chilenos presenta un alto grado estrés, y que el $27 \%$ de la población había colapsado ante situaciones difíciles de manejar. Al analizar los datos por nivel socioeconómico, el 13,9\% de los miembros del grupo $\mathrm{ABC} 1$ presentó un alto grado de estrés, mientras en los sectores $\mathrm{D}$ y E, la cifra se dobla, alcanzando el 30,3 por ciento. De ahí se entiende que el principal factor de estrés que detectó el estudio haya sido, por lejos, el alza del costo de la vida.

23 El año recién pasado fue el motivo central de movilizaciones de los mineros en Chuquicamata, de la Federación Nacional de Asociaciones de Funcionarios Técnicos de los Servicios de Salud (FENTESS), de la Confederación Nacional de Funcionarios Municipales (ASEMUCH), del Colegio de Profesores, entre otras organizaciones gremiales. 
bajo están desigualmente distribuidos, si la inestabilidad no es igual para todos, entonces los problemas del trabajo permanecerán insolubles mientras el trabajo no sea realmente el criterio para repartir la riqueza (Collin, 2000). Una discusión de este tipo no se puede concentrar solamente en políticas para mejorar la situación de «los de abajo» sin tocar a los que «están arriba». De ser esa la fórmula, sostenida incluso por algunos economistas críticos, ${ }^{24}$ se mantendrán inmunes las estructuras sociales de la economía. Desmontarlas requiere apuntar a su base técnica, a las teorías contemporáneas de la administración, que son las bases ideológicas para justificar las diferencias sociales, pero que se revelan imprecisas, por ejemplo, cuando tienen que describir los criterios de cálculo para los ingresos de los directivos y los cuadros de managers y ejecutivos. ${ }^{25}$ De alguna forma, los desastres financieros y el destino de las ayudas fiscales que han entregado algunos gobiernos de los países centrales a la banca privada han servido para hacer pública la inaceptable lógica del capital financiero. Pero hay que tener en cuenta que las ideologías del libre mercado han decantado en las formas de pensar la sociedad de parte importante de la población, sobre todo de los sectores más favorecidos por sus beneficios.

Resolver los problemas de la estabilidad conecta con otro de los temas que trataron las conversaciones: los dilemas del tiempo. Para los jóvenes que trabajan, el problema del tiempo se modula desde la experiencia personal, de los problemas que acarrea en términos de cansancio, estrés, ${ }^{26}$ o la imposibilidad de «hacer otras cosas» que no sean

24 Es lo que parece plantear Gorz cuando dice que «lo que está en tela de juicio no son los ingresos individuales motivados por la ganancia capitalista» (Gorz, 1996)

25 Los manuales sobre administración de recursos humanos, en ambos casos se basan en especulaciones sobre los desempeños futuros de las empresas, la información de encuestas de mercado y una absurda sobrevaluación de su papel en la productividad. Todos estos mecanismos disfrazan el criterio de fondo: la reproducción de las estructuras sociales de la economía. ¿Qué otra cosa justifica que los altos ejecutivos chilenos obtengan uno de los mayores salarios del mundo, incluso por sobre los de ejecutivos de Emiratos Árabes Unidos y Suiza? (cf. International Geographical Salary Differentials, 2005).

26 La alta prevalencia de enfermedades psicosomáticas asociadas al estrés laboral - afectan a uno de cada cuatro trabajadores - hacen de la reducción de los tiempos de trabajo una necesidad de salud pública que se justifica incluso presupuestariamente. 
trabajar. Aunque no sea físico, el trabajo es un gasto de energía para el trabajador y un desgaste por su prolongación en el tiempo (Ibáñez, 1999). Los sueldos se calculan por el valor de la hora de trabajo. El discurso económico trata de plantear una relación lineal y directa que empareja artificialmente tiempo y salario: más tiempo de trabajo, más salario. Es la ecuación que sostiene muchas nuevas formas de relaciones laborales en los servicios - comisión por metas, etc.-, pero son fórmulas de suma cero: puede tener ventajas monetarias, pero es siempre a expensas del tiempo de trabajo y la estabilidad psicológica que da la certeza sobre el monto del ingreso real (Vergara, 1995). Los datos empíricos lo confirman: los salarios de quienes trabajan más horas son inferiores a los de quienes trabajan menos (Echeverría y Jeria, 2005). Su inconsistencia, por lo tanto, repone al problema del tiempo como piedra angular en la superación de los conflictos del trabajo. Más en Chile, que además de encabezar la lista de los países con jornadas laborales más largas, ${ }^{27}$ no logra salir de las 10 primeras naciones del mundo con peores índices en la distribución de la riqueza.

Políticas de reducción de los tiempos de trabajo tienen un doble impacto que son sumamente importantes para las generaciones jóvenes: mejoran las condiciones de vida de los trabajadores y también permiten superar el desempleo. A pesar de eso, las «políticas del tiempo» que se han discutido en algunos países han preferido apuntar a una reorganización de los tiempos, no a su reducción (Boulin, 1996). En varios países de la Comunidad Europea se han diseñado mecanismos para repartir los tiempos de trabajo entre los trabajadores activos - bonos de tiempo, distribución de feriados, etc.- , pero sin tocar los tiempos de trabajo. Con eso se pierde la posibilidad de disminuir el desempleo reduciendo los tiempos de trabajo y se mantiene al trabajo como dominador del tiempo: los tiempos de descanso y de ocio - fines de semana, vacaciones - son tiempos regulados por el trabajo que niegan la liberación diaria del tiempo de otium, que es el tiempo para la vida social y la producción de cultura, la creación y la política (Milner, 2003).

En Chile se ha dado una combinación: se aplicó una ley sui generis que traspasó los días festivos de media semana al lunes correspondiente - para evitar las pérdidas en millones de dólares que se asocian a los «días sandwich»—, y otra ley que redujo de 48 a 45 el máximo de horas semanales. Mala señal fue para esta normativa que su trámite

27 En 2003 Chile superó en horas de trabajo anuales en 25\% a los países europeos, en $15 \%$ a Japón y en $14 \%$ a Estados Unidos. 
legislativo tuviera problemas de tiempo: la resistencia del empresariado retrasó más de tres años su entrada en vigencia. ${ }^{28}$ Por esa resistencia, los sectores sindicales presagiaron un mal destino a la nueva norma. Y no se equivocaban: dos tercios de las infracciones laborales y previsionales cometidas por las empresas privadas son por infringir las normas que regulan la jornada de trabajo y los descansos (Encla, 2008). ${ }^{29}$ Prácticas como éstas solamente demuestran que la apropiación del tiempo ajeno sigue siendo la base del poder (Riechmann y Recio, 1997). Por lo mismo, mantienen a la reducción de los tiempos de trabajo socialmente necesarios como fuente para la utopía. Hace cerca de tres décadas Marcuse depositaba su esperanza en la revolución tecnológica: el maquinismo, la robotización, la informática harían cada vez menos necesario el trabajo. Pero los procesos históricos siguieron derroteros paradójicos: en vez de aprovechar los inventos ahorradores de trabajo para liberar a las personas de tareas penosas y reducir al mínimo el calendario laboral, las máquinas se han convertido en un factor más de separación entre quienes tienen y quienes no tienen trabajo (Naredo, 2002). Pero el derrotero histórico no invalida la tesis. Menos ahora. En la actualidad existe un nivel suficiente de tecnología como para producir alimentos y bienes para toda la humanidad. El problema es de economía política: la necesidad de las empresas de mantener un ejército de reserva disponible para sostener el temor a la escasez de trabajo (Collin, 1998). No es casual que junto al despido de trabajadores, la extensión de la jornada sea la segunda estrategia más usada por las empresas para capear la crisis y mantener las ganancias, sobre todo las grandes empresas (Encla, 2008). ${ }^{30}$

28 El empresariado asume que sólo la educación es factor de productividad, y con ese argumento estrecho y sin base empírica evita asumir la evidencia que ha demostrado los efectos positivos de la reducción de las jornadas sobre la productividad: varios estudios del INE y el Banco Central han demostrado que la reducción de la jornada laboral no ha afectado la productividad; al contrario, se ha mantenido e incluso mejorado entre un $4 \%$ y un $6 \%$ (Echeverría y Jeria, 2005).

29. El 1 de mayo de 2008 el sindicato de Telefónica denunció públicamente la manipulación de los contratos de trabajadores mediante el despido y la ampliación de la modalidad del teletrabajo que flexibilizó la norma para los departamentos e hicieron que las 45 horas semanales corriera solamente para la alta dirección (cf. SITP, 2008).

30 Las grandes empresas presentan los promedios de horas de trabajo más bajas, pero son las que más la flexibilidad de las jornadas laborales, las 
Ahora bien, un paso inevitable para una política de reducción de los tiempos de trabajo es la discusión sobre las necesidades. La paradoja inevitable entre trabajo y liberación es que sólo es posible liberarse del trabajo por el trabajo mismo. Las necesidades impiden otra opción: el tiempo de trabajo está determinado por lo socialmente necesario. Ahí la importancia de preguntarse por la necesidad: cómo se define lo necesario, qué es verdadera o falsa necesidad. La respuesta obligaría varios capítulos.

El debate actual gira en torno a la pregunta sobre hasta qué punto las necesidades son o no socialmente producidas. Las necesidades fisiológicas tienen un límite calculable. ${ }^{31} \mathrm{Su}$ exceso hace obeso. Lo que es socialmente producido son los satisfactores, hoy en medio del debate sobre alimentación natural o industrial, cultivos tradicionales o transgénicos... El problema son las necesidades no fisiológicas. Preguntas como: ¿es realmente necesario un auto o un reproductor de DVD?, tienen una respuesta más difícil, pero la dificultad solamente confirma el componente social que está en la base de su construcción. «Toda necesidad está socialmente condicionada por el simple hecho de que surge en un campo de posibilidades sociales», decía Gorz (1964). Por eso una política de reducción del tiempo de trabajo exige repensar tanto las necesidades como las formas de satisfacerlas. Ambas son decisiones éticas y políticas. Exige pasar de un modelo productivista a uno socialmente sustentable. No puede ser, como señala el mismo André Gorz, que el productivismo se sostenga introduciendo a los productos piezas deliberadamente desechables si su costo es igual o incluso superior a piezas que garantizan durabilidad (Gorz, 1996). Lo único que hace esa estrategia es reproducir artificialmente una demanda a la producción y una necesidad de mantener cooptado al trabajo. Es esta irracionalidad global del sistema llevada al extremo lo que se necesita desmontar, lo que de paso también implica desmontar

que más usan el sobretiempo, las jornadas parciales, el trabajo en domingo y casi todas las formas de distribución inusual del tiempo de trabajo. Es decir, cuando las empresas deciden flexibilizar la jornada lo hacen intensivamente, involucrando proporciones importantes de su personal, que además tienen menos tiempo para almorzar y para otras pausas (Encla, 2008).

31 De hecho las políticas de planificación del desarrollo de los años sesenta aplicaban como una de sus variables las kilocalorías diariamente necesarias para las distintas edades. 
los discursos publicitarios y la recubierta simbólica de mercancías y consumos de entretención, tan caros a las prácticas de consumo de segmentos juveniles. ${ }^{32}$

La alternativa al productivismo es desacelerar la producción y reducir las cantidades del producto. Es una fórmula que sirve para bajar los ritmos de producción y reducir los tiempos de trabajo, minimizar la cantidad de energía humana y natural consumida y evitar su desgaste innecesario. Los movimientos ecologistas cuestionan justamente este punto, aunque sus acciones parecen todavía atomizadas en grupos activistas, en su gran mayoría jóvenes y estudiantes que a la indiferencia generalizada, suman las prácticas antisociales de las empresas, ${ }^{33} \mathrm{y}$ la contradicción de los sindicatos. ${ }^{34}$ La tensión obliga a una definición: o se defiende «la pega» o se defiende una organización del trabajo social y ecológicamente sustentable. ${ }^{35}$ Este último criterio es la única

32 Una anécdota reciente grafica la irracionalidad llevada al extrema: «La cantante y diseñadora Victoria Beckham aprovechó una fugaz visita a Milán para gastarse cerca de 250 millones de pesos en un sólo día. Entre las compras incluyó 20 pares de zapatos de la firma Dolce \& Gabbana, 12 pares de lentes de sol de Versace y un reloj Rolex valorado en 200 millones de pesos. «Los artículos de esas tiendas maravillosas están diciendo 'ven y cómprame, ven y cómprame'. Y, total, así ayudo a la economía» (Cooperativa digital, 11 de enero, 2010). Lo complejo es que esta frugalidad en el consumo de la clase opulenta y que no trabaja se convierten en poderosos ejemplos para la que sí trabaja.

$33 \mathrm{Al}$ respecto, revisar los artículos difundidos en varios medios digitales y observatorios ambientalistas sobre el conflicto de Pascua Lama y las acciones de CELCO en las localidades de Mehuín y Missisipi.

34 Es el caso de los sectores subcontratistas de las forestales, que han venido dando una lucha sectorial sin grandes resultados contra las empresas papeleras, pero, al mismo tiempo, defienden a las empresas frente a los cuestionamientos de los grupos ecologistas. Particularmente reveladoras sobre este punto son las escenas del documental Ciudad de papel, de Claudia Sepúlveda, en que las manifestaciones de los grupos ecologistas que se manifestaban contra la muerte masiva de cisnes que habitaban en Santuario de la Naturaleza Carlos Anwandter, son intimidadas por caravanas de camiones con trabajadores forestales ligados a Celulosa Arauco haciendo sonar sus sierras eléctricas.

35 La discusión sobre sustentabilidad ecológica y social ha pasado del predominio de teorías que ponen la calidad de vida antes que la protección de la naturaleza al de teorías que invierten la relación para demostrar que no se puede detener la degradación de los territorios si no se re- 
forma para que la satisfacción de las necesidades genere un sistema de trabajo basado en lazos sociales y valores de igualdad y justicia, y la forma más idónea para que las nuevas generaciones puedan participar plenamente de la vida económica, social y política. Así el valor de trabajar no se reduce solamente a la producción de bienes transables en el mercado: también se vuelve valioso lo que se realiza en la red de relaciones que se establecen desde la producción al consumo de bienes (Harribey, 2002). De esa forma el trabajo y la vida cobran sentido (Antunes, 2000). Las tentativas de transformación por la vía de iniciativas cooperativas de las que se habló en los grupos es consonante con la apertura de nuevas formas de pensar y hacer la organización del trabajo. De alguna manera esas ideas son bastante próximas a las propuestas de Razeto sobre economía solidaria: generar experiencias de organizaciones económicas que descansen en principios de justicia y solidaridad entre los miembros de unidades productivas autogestionadas que, en la medida que se legitimen y demuestren su eficiencia, le pueden ir quitando espacio al sector empresarial que controla todos los mercados. ${ }^{36}$ Por lo mismo, es perfectamente posible pensar en políticas de trabajo para jóvenes que fomenten la creación de unidades de trabajo solidarias y cooperativas que se puedan extender como siste$\mathrm{ma} / \mathrm{red}$ de unidades coordinadas. Las políticas de emprendimiento juvenil que han aplicado los organismos de inversión social son un mal sucedáneo: fomentan el trabajo por cuenta propia, pero con lógicas individualizadas y orientadas a actividades escasamente productivas que no logran abrir el círculo de la pobreza. Y es que la solución del problema del trabajo para los jóvenes no pasa por políticas de empleo juvenil, sino por una reorganización del conjunto de la economía y la sociedad. De alguna manera la coincidencia temática entre la conversación de los jóvenes y la reflexión social y filosófica sobre el trabajo es un punto a favor: supone un piso común que facilita el diálogo. Pero también es un desafío porque obliga al trabajo de investigación a

suelve antes la calidad de vida de los grupos humanos. Foladori plantea que ambas formulaciones se concentran en la esfera técnica del trabajo - la relación humano/naturaleza-, pero evitan tocar las relaciones sociales de producción, cuando son éstas precisamente las que restringen las posibilidades de que cambios en las relaciones técnicas alcancen la sustentabilidad social (Foladori, 2002).

36 Para revisar los trabajos de Luis Razeto, se puede visitar su página web: www.luisrazeto.net. 
asumir un papel activo en la discusión sobre el trabajo. La investigación social puede generar espacios de diálogo que pueden servir para formar reflexión y - por qué no- discursos colectivos.

Resulta ilustrativo en este sentido que al cierre de un grupo los participantes sintieran que habían tenido la posibilidad de darse cuenta que compartían los mismos problemas y que todos tenían «la misma base». El intento por articular un discurso generacional es sintomático: muestra un anhelo utópico por transformar las lógicas de organización del trabajo. Quedaría por ver en qué medida se traducen en acción. Las condiciones están. Como bien plantea Abad (2005), la imposibilidad de cerrar la etapa de juventud y la «juvenilización» de la población adulta diluyen los límites intergeneracionales y emparejan las condiciones de existencia. Después de todo, los relatos muestran que son las relaciones con los compañeros de trabajo y no con la empresa los vínculos más fuertes y significativos, y en eso las fronteras generacionales se borran. Esa puede ser una base para construir una conciencia que supere la dispersión que imponen las reingenierías administrativas y las políticas de trabajos diferenciadas generacionalmente. Las organizaciones sindicales han tratado de tomar la discusión sobre la negociación colectiva como una bandera de lucha. De alguna forma, la contradicción del discurso empresarial le entrega un precedente: mientras pone cortapisas a la formación de organizaciones sectoriales o sindicatos interempresas, no tiene problemas para asociarse bajo cuerda y crear monopolios virtuales. ${ }^{37}$ Algo es algo.

VALPARAÍSO (CHILE), DICIEMBRE 2009

RECIBIDO: DICIEMBRE 2009 ACEPTADO: DICIEMBRE 2009

37 El caso más reciente fue el de colusión entre las grandes cadenas farmacéuticas chilenas. Después de repartirse el mercado en sólo tres grandes cadenas farmacéuticas, las empresas acordaron un virtual monopolio que les permitió fijar altos precios y que solamente se hizo público tras la «traición» de los ejecutivos de una de las cadenas implicadas para reducir por delación compensada las sanciones de la investigación que estaban llevando los organismos fiscalizadores. 


\section{REFERENCIAS BIBLIOGRÁFICAS}

ABAD, Miguel (2005): «Políticas de juventud y empleo juvenil: el traje nuevo del rey». Última Década N$^{\circ} 22$. Valparaíso: Ediciones CIDPA.

Agulló, EsteBAN (1997): Jóvenes, trabajo e identidad. Oviedo: Universidad de Oviedo.

Albert, Cecilia; J. Pablo Juárez, Rosario Sánchez y luis Toharía (1998): «Las transiciones de los jóvenes de la escuela al mercado de trabajo: un análisis de flujos». En Cuadernos de Trabajo del Instituto Valenciano de Investigaciones Económicas.

ANTUNES, RiCARDO (2003): «iAdiós al trabajo? Los nuevos proletarios del mundo en el cambio de siglo». Ponencia VI Encuentro de Revistas Marxistas. Montevideo.

_ (2000): «El caracol y su concha: ensayo sobre la nueva morfología del trabajo». Revista Herramienta $\mathrm{N}^{\circ} 31$. Buenos Aires.

BAUMAN, ZYGMUNT (2003): Modernidad líquida. Buenos Aires: FCE.

BELL, DANIEL (1976): El advenimiento de la sociedad post-industrial: un intento de prognosis social. Madrid: Alianza Editorial.

BOLTANSKI, LUC y ÉVE CHIAPELLO (2002): El nuevo espíritu del capitalismo. Madrid: Akal.

BOULIN, JEAN-YVES (1996): «Las políticas del tiempo de trabajo. El caso de Europa». Ekonomiaz ํo34. País Vasco.

Bourdieu, PiERRE (1988): La distinción. Criterio y bases sociales del gusto. Madrid: Taurus.

Brunner, José; Gregory Elacqua, ANTHONy TIllet, JaViera Bonnefoy, Soledad Gonzalez, Paula Pacheco y Felipe Salazar (2005): Guiar el mercado. Informe sobre la educación superior en Chile. Viña del Mar: Universidad Adolfo Ibáñez.

CANDElero, MANUEl (2001): «El impacto tecnológico: trabajo decente o vida decente». VIII Congreso Nacional del Equipo Federal del Trabajo. Catamarca.

Casal, Joaquim; Rafael Merino y Maribel García (2008): Pasado y futuro del estudio sobre la transición de los jóvenes. Barcelona: UAB.

COLLIN, DENIS (1998): «Las tesis sobre "el fin del trabajo": ideología y realidad social». Revista Herramienta $\mathrm{N}^{\circ} 6$. Buenos Aires.

DÁvila, Oscar; Felipe GHIARdo y Carlos Medrano (2006): Los desheredados. Trayectorias de vida y nuevas condiciones juveniles. Valparaíso: Ediciones CIDPA (segunda edición aumentada).

De la GaRza, EnRIQUe (2006): Teorías sociales y estudios del trabajo: nuevos enfoques. México: Anthropos. (2001): «Problemas clásicos y actuales de la crisis del trabajo». En JULIO NEFFA y ENRIQUE DE LA GARZA (compiladores): El trabajo del futuro. El futuro del trabajo. Buenos Aires: CLACSO. 
De Moura Castro, Claudio; Martin Carnoy y Laurence Wolf (2006): Las escuelas de secundaria en América Latina y el Caribe y la transición al mundo del trabajo. Washington: BID.

Dirección DEL TRABAJO (2008): Encuesta laboral 2008. Santiago: Departamento de Estudios, Dirección del Trabajo.

ECHEVERRÍA, MAGDALENA y LAURA JERIA (2005): «Beneficios de reducir la jornada e inequidades por resolver». Temas Laborales №23. Santiago: Dirección del Trabajo.

ESCOBAR, ARELI (2005): «Trabajo, desocupación y configuración de la subjetividad laboral en la región del Biobío Chile». Revista Trabajo y Sociedad $\mathrm{N}^{0} 7$. Santiago del Estero.

ESPINOZA, VICENTE (2006): «La movilidad ocupacional en el Cono Sur: oportunidades y desigualdad social». Revista de Sociología de la Universidad de Chile $\mathrm{N}^{\circ} 20$. Santiago: Universidad de Chile.

FAWCETT, CAROLINE (2002): Los jóvenes latinoamericanos en transición: un análisis sobre el desempleo juvenil en América Latina y el Caribe. Washington: BID

FOLADORI, GUILlERMO (2002): «Avances y límites de la sustentabilidad social». Economía, Sociedad y Territorio Nº12.

Gracia, Francisco; Pilar Martín, IsABel Rodríguez y José María PEIRÓ (2001): «Cambios en los componentes del significado del trabajo durante los primeros años de empleo: Un análisis longitudinal». Anales de Psicología No2. Murcia: Universidad de Murcia.

GARCÍA, MARIBEL; RAFAEL MARINO y JOAQUIM CASAL (2006): «Transiciones de la escuela al trabajo tras la finalización de la enseñanza secundaria obligatoria».

GORZ, ANDRÉ (1996): Miserias del presente, riqueza de lo posible. Buenos Aires: Paidós.

(1964): «Lo superfluo antes que lo necesario». En: www.eumed.net.

Huws, URSULA (2003): "The making of a cybertariat (virtual work in a real world)». Monthly Review Press. Londres.

IBÁÑEZ, JESÚS (1997): A contracorriente. Madrid: Fundamentos.

Jacinto, Claudia; Mariela Wolf, CARla Bessega y María Eugenia LONGO (2002): Jóvenes, precariedades y sentidos del trabajo. Buenos Aires: Asociación Argentina de Especialistas en Estudios del Trabajo.

JAMESON, FREDRIC (2004): «La política de la utopía». New Left Review No25. Madrid: Akal.

KORNBLIT, ANA LÍA (1995): «Representaciones sociales y valores de los jóvenes argentinos en relación con el trabajo». Estudios del Trabajo No8.

MARCuSE, Herbert (1969): Un ensayo para la liberación. Cuadernos de Joaquín Mortiz. México.

MÉDA, DOMINIQUE (1995): El trabajo: un valor en peligro de extinción. Madrid: Gedisa. 
MONTES CATÓ, JUAN (2005): «Subordinación y dominación en los espacios de trabajo. Estudio sobre la disciplina y sus formas de expresión». Athenea Digital No8.

NeFFA, JUliO CÉSAR (2001): «Presentación del debate reciente sobre el fin del trabajo». En JULIO NEFFA y ENRIQUE DE LA GARZA (compiladores): El trabajo del futuro. El futuro del trabajo. Buenos Aires: CLACSO.

NAREDO, JosÉ Miguel (2002): «Configuración y crisis del mito del trabajo». Revista Scripta Nova $\mathrm{N}^{\mathrm{o}} 119$. Barcelona: Universidad de Barcelona.

NúÑEZ, IVÁN y ROBERTO GUTIÉRREZ (2004): «Classism, discrimination and meritocracy in the labor market: the case of Chile». Documento de Trabajo No208. Santiago: Departamento de Economía Universidad de Chile.

Orellano, Miguel y ERnEStina Rosendo (2004): «Escuela, trabajo y transiciones juveniles: la década de los 90 como bisagra para pensar una relación conflictiva». Cuadernos de Antropología Social N¹9. Buenos Aires: UBA.

PÉREZ ISLA, JosÉ A. y MARITZA ARTEAGA (2003): «Los nuevos guerreros del mercado: trayectorias laborales de jóvenes buscadores de empleo». México.

Petras, James (1996): «Padres-hijos. Dos generaciones de trabajadores españoles». Ajo Blanco No3.

REINECKE, GERHARD y MARÍA Elena VALENZUELA (2008): Distribución y mercado de trabajo: un vínculo ineludible. Santiago: OIT.

— у JACOBO VELASCO (2005): «Chile: informe de empleo para el año 2005». Santiago: OIT.

RIESCO, MANUEL (1999): "Chile necesita un nuevo consenso ético». En Chile, desafios éticos del presente. Santiago: PNUD.

RIFKIN, JEREMY (1996): El fin del trabajo. Nuevas tecnologías contra puestos de trabajo y el nacimiento de la era posmercado. Buenos Aires: Paidós.

SAINT-PAUL, GiLlES (2007): «Estrategias alternativas para combatir el desempleo: Lecciones de la 'experiencia europea'». Revista Estudios Públicos $\mathrm{N}^{\mathrm{o}} 108$. Santiago: CEP.

SANCHÍs, ENRIC (1988): «Valores y actitudes de los jóvenes ante el trabajo».

SENNET, RICHARD (2000): La corrosión del carácter. Las consecuencias personales del trabajo en el nuevo capitalismo. Barcelona: Anagrama.

SEPÚLVEDA, LEANDRO (2006): «Incertidumbre y trayectorias complejas: un estudio sobre expectativas y estrategias laborales de jóvenes y adultos jóvenes en Chile». En JÜRGEN WELLER (editor): Los jóvenes y el empleo en América Latina: desafios y perspectivas ante el nuevo escenario laboral. Bogotá: CEPAL/GTZ/Mayol Ediciones.

SunKel, OsVALDO (2007): «En busca del desarrollo perdido». En: Repensar la teoría del desarrollo en un contexto de globalización. Homenaje a Celso Furtado. Santiago: CEPAL. 
Touraine, Alain (1971): La sociedad post-industrial. Barcelona: Ariel.

VERGARA, Rodrigo (1995): «Reformas laborales: elementos para el análisis». Revista Estudios Públicos No59. Santiago: CEP.

WELLER, JÜRGEN (2003): «La problemática inserción laboral de los y las jóvenes». Serie Macroeconomía del Desarrollo N²8. Santiago: CEPAL.

WOLFF, MATÍAS (2005): «La identidad y el sentido del trabajo. Consecuencias culturales e identitarias de la situación actual del trabajo en Chile: el caso de los empleados bancarios». Memoria para optar al título de antropólogo social. Santiago: Universidad de Chile. 